\title{
EXTRA LARGE G-PROTEIN 2 (XLG2) mediates cell death and hyperimmunity via a novel, apoplastic ROS-independent pathway in Arabidopsis thaliana
}

\author{
Elena Petutschnig ${ }^{1,2}$, Julia Anders ${ }^{1}$, Marnie Stolze ${ }^{1}$, Christopher Meusel ${ }^{1}$, Ronja Hacke ${ }^{1}$, Melina \\ Schwier ${ }^{1}$, Anna-Lena Gippert ${ }^{1}$, Samuel Kroll ${ }^{1}$, Patrick Fasshauer ${ }^{1}$, Marcel Wiermer ${ }^{3}$, Volker \\ Lipka $^{1,2}$ \\ ${ }^{1}$ Department of Plant Cell Biology, Albrecht-von-Haller-Institute for Plant Sciences, Georg-August-University \\ Göttingen, Julia-Lermontowa-Weg 3, 37077 Göttingen, Germany. \\ ${ }^{2}$ Central Microscopy Facility of the Faculty of Biology \& Psychology, Georg-August-University Göttingen, Julia- \\ Lermontowa-Weg 3, 37077 Göttingen, Germany. \\ ${ }^{3}$ Molecular Biology of Plant-Microbe Interactions Research Group, Albrecht-von-Haller-Institute for Plant Sciences, \\ Georg-August-University Göttingen, Julia-Lermontowa-Weg 3, 37077 Göttingen, Germany.
}

Authors for correspondence:
Elena Petutschnig
Volker Lipka
Tel: +4955139177805
Email: Elena.Petutschnig@biologie.uni-goettingen.de
Tel: +4955139177801
Email: Volker.Lipka@biologie.uni-goettingen.de

\section{Key words:}

EXTRA LARGE G-PROTEIN 2 (XLG2), CHITIN ELICITOR RECEPTOR KINASE 1 (CERK1), cerk1-4, heterotrimeric G-protein, cell death, ROS, Arabidopsis, powdery mildew 


\section{ABSTRACT}

- Heterotrimeric G-Proteins are signal transduction complexes comprised of three subunits, $G \alpha, G \beta$ and $G \gamma$, and are involved in many aspects of plant life. The non-canonical Ga subunit XLG2 mediates PAMP-induced ROS generation and immunity downstream of PRRs. A mutant of the chitin receptor component CERK1, cerk1-4, maintains normal chitin signalling capacity, but shows excessive cell death upon infection with powdery mildews. We identified XLG2 mutants as suppressors of the cerk1-4 phenotype.

- We generated stably transformed Arabidopsis lines expressing Venus-XLG2 and numerous mutated variants. These were analysed by confocal microscopy, Western blotting and pathogen infection. We also crossed cerk1-4 with several mutants involved in immunity and analysed their phenotype. Phosphorylation of XLG2 was investigated by quantitative proteomics.

- Mutations in XLG2 complex partners AGB1 and AGG1 have a partial cerk1-4 suppressor effect. The cerk1-4 phenotype is independent of NADPH oxidase-generated ROS, BAK1 and SOBIR1, but requires PUB2. XLG2 mediates cerk1-4 cell death at the cell periphery. Integrity of the XLG2 N-terminal domain, but not its phosphorylation, is essential for correct XLG2 localisation and cerk1-4 signalling.

- Our results suggest that XLG2 transduces signals from an unknown cell surface receptor that activates an apoplastic ROS-independent cell death pathway in Arabidopsis. 


\section{INTRODUCTION}

Heterotrimeric G-proteins are signal transducing complexes which are evolutionarily conserved in eukaryotes and play important roles in many different pathways. They consist of three subunits, $G \alpha, G \beta$ and $G \gamma$, and their basic mechanism of action has been elucidated in metazoans, where they are activated by membrane bound G-protein coupled receptors (GPCRs). The G $\alpha$ subunit has GTPase activity and in the inactive, GDP-bound form associates with G $\beta$ and Gy, which form a stable heterodimer. Ligand binding of GPCRs leads to Ga nucleotide exchange, and the GTP-bound $G \alpha$ dissociates from G $\beta \gamma$. Subsequently, both $G \alpha$ and the $G \beta \gamma$ dimer can relay signals to downstream targets. Signal transduction is terminated by the GTPase activity of Ga, which can be enhanced by GTPase Activity Promoting proteins (GAPs), and leads to re-association of the ternary complex (Oldham \& Hamm, 2008; Pandey, 2019).

Plants possess canonical $G \alpha, G \beta$ and $G \gamma$ subunits represented by GPA1, AGB1 and the redundantly acting AGG1/AGG2 in Arabidopsis. In addition, they contain plant-specific Gproteins, such as EXTRA LARGE G-PROTEINS (XLG1, 2 and 3 in Arabidopsis), a class of alternative $\mathrm{G} \alpha$ subunits with an $\mathrm{N}$-terminal domain of unknown function. Similar to metazoans, signal transduction by plant heterotrimeric G-proteins is required for many processes, including growth, development, hormone and sugar sensing as well as responses to biotic and abiotic stresses (reviewed by Pandey, 2019; Zhong et al., 2019; Ofoe, 2021; Zhang et al., 2021). However, bona fide GPCRs have not been identified in plants and relatively little is known about the regulatory mechanisms. In contrast to animal heterotrimeric G-proteins, the canonical Arabidopsis Ga subunit GPA1 is inherently GTP-bound in vitro and likely constitutively active in plants. Signalling is thought to be controlled through deactivation via GAPs (Urano \& Jones, 2014). For the Extra Large G-protein XLG2, only weak GTP binding / GTPase activity has been observed in vitro (Heo et al., 2012; Lou et al., 2020) and recent studies suggest that in planta, both GPA1 and XLG2 can fulfil many of their roles independently of nucleotide exchange (Maruta et al., 2019; Maruta et al., 2021).

Mounting experimental evidence indicates that plant heterotrimeric G-proteins act downstream of receptor-like kinases (RLKs) and are regulated by phosphorylation (Aranda-Sicilia et al., 2015; Roy Choudhury \& Pandey, 2016; Tunc-Ozdemir et al., 2016; Pandey, 2020). A well-studied example is the complex consisting of XLG2, AGB1 and AGG1/AGG2 that transduces signals from pattern recognition receptors (PRRs). Liu et al. (2013) showed that agb1 and agg1 agg2 mutants, but not gpa1 plants, have reduced immune responses to pathogen associated molecular patterns (PAMPs) such as flagellin, EF-Tu and chitin. XLG2 and XLG3 were identified as the Ga subunits that function in these defense pathways (Maruta et al., 2015). XLG2 was then shown to directly interact with the flagellin receptor complex components FLAGELLIN SENSING 2 (FLS2) and BOTRYTIS INDUCED KINASE 1 (BIK1) (Liang et al., 2016). The interaction with G-proteins stabilizes BIK1, presumably through inhibition of E3 ubiquitin ligases that target BIK1 for degradation (Wang et al., 2018). Consequently, xlg2 xlg3 mutants contain less BIK1, leading to a decreased PAMP-induced ROS-burst by apoplastic NADPH oxidases. Upon flagellin treatment, XLG2 is 
phosphorylated in the $\mathrm{N}$-terminal domain (possibly by BIK1) and dissociates from the receptor. Phosphorylation of XLG2 at four specific sites is required for full flagellin-induced ROS generation, even though this modification has no impact on BIK1 protein stability. Therefore, XLG2 is thought to modulate ROS generation via a second line of action, through direct interaction with the NADPH oxidase RBOHD (Liang et al., 2016). Moreover, XLG2 is known to interact with the E3 ubiquitin ligases PLANT U-BOX 2 (PUB2) and PUB4 (Wang et al., 2017), which are also required for a full PAMP-induced ROS-burst (Desaki et al., 2019; Derkacheva et al., 2020).

Further indications for an involvement of XLG2, AGB1 and AGG1/AGG2 in immune receptor signalling come from a suppressor screen performed with a mutant of the BAK1 INTERACTING RECEPTOR-LIKE KINASE 1 (BIR1). BIR1 is a LRR-RLK that interacts with and probably negatively regulates BAK1 (BRI1-ASSOCIATED RECEPTOR KINASE 1). bir1 knock-out mutants develop spontaneous cell death and show constitutive immune responses that are dependent on BAK1 and another LRR-RLK involved in immune signalling, SUPPRESSOR OF BIR1-1 (SOBIR1) (Gao et al., 2009; Liu et al., 2013; Liu et al., 2016). Mutations in XLG2, AGB1 and AGG1/AGG2, but not GPA1, suppress the phenotype of bir1 knockout plants (Liu et al., 2013; Maruta et al., 2015).

We previously identified and characterized cerk1-4, a mutant with an amino acid exchange in the extracellular domain of the Arabidopsis chitin receptor component CHITIN ELICITOR RECEPTOR KINASE 1 (CERK1). cerk1-4 plants show normal chitin signalling, but exhibit a hyperimmunity phenotype. Upon inoculation with powdery mildews, cerk1-4 mutants display excessive cell death formation and accumulation of the plant defence hormone salicylic acid (SA). Consequently, they do not support macroscopically visible growth of adapted powdery mildew species. The phenotype of cerk1-4 plants is associated with altered receptor processing and is conferred by the N-terminal part of the CERK1-4 protein. Unlike chitin signalling, manifestation of the cerk1-4 phenotype does not require CERK1 kinase activity (Petutschnig et al., 2014). Here we show that cerk1-4 hyperimmunity is suppressed by mutations in XLG2 and reduced in cerk1-4 agb1 and cerk1-4 agg1 plants. The formation of the cerk1-4 phenotype does not require BAK1 or SOBIR1 and is independent of NADPH-oxidase mediated ROS-generation. In depth cell biological and biochemical analyses of XLG2 mutant variants show that XLG2 fulfils its function in cerk1-4 signalling at the cell periphery. This novel role of XLG2 does not require its GTPase activity, but an intact $\mathrm{N}$-terminal domain. Structural integrity of the $\mathrm{N}$-terminal domain is also important for interaction with AGB1 and proper XLG2 phosphorylation. Finally, we show that the XLG2 interactor PUB2 contributes to cerk1-4 cell death.

\section{MATERIALS AND METHODS}

\section{Plant growth conditions and pathogen infection assays}

Arabidopsis thaliana (L.) Heynh. plants were grown under short day conditions (8h photoperiod) at $22^{\circ} \mathrm{C}$ (day) $/ 18^{\circ} \mathrm{C}$ (night), $65 \%$ relative humidity and a light intensity of approximately $150 \mu \mathrm{mol}$ $\mathrm{m}^{-2} \mathrm{~s}^{-1}$. Four-week-old plants were inoculated with either Blumeria graminis (DC.) Speer f.sp. 
hordei (Bgh) or Erysiphe cruciferarum Opiz ex L. Junell using a settling tower. Pictures and samples were taken at 5-10 dpi for Bgh and 7-14 dpi for E. cruciferarum infections.

\section{cerk1-4 suppressor screen and mapping of les1}

Seeds of cerk1-4 (Petutschnig et al., 2014) were mutagenized with ethyl methanesulfonate (EMS) and resulting $\mathrm{M} 2$ plants were inoculated with either Bgh or E. cruciferarum. Plants that did not show any macroscopically visible cell death were selected and confirmed as suppressors in the M3 generation. For mapping, a strategy adapted from (Hartwig et al., 2012) was used. The les1 mutant was backcrossed to cerk1-4 and approximately $250 \mathrm{~F} 2$ plants were scored for suppression of the powdery mildew-induced cell death phenotype. A pool of 31 clear suppressor plants and a pool of cerk1-4 plants grown in parallel were subjected to $100 \mathrm{bp}$ paired end Illumina sequencing. A coverage of approximately $40 \mathrm{x}$ was achieved for both samples. Using the CLC genomics workbench software, the reads were mapped to the Col-0 TAIR10 genome and SNPs with a frequency of $20 \%$ or higher were called. SNP tables were exported to Microsoft Excel, where SNPs present in cerk1-4 were subtracted from SNPs found in les1. For the remaining SNPs, the frequency was plotted against their chromosomal position (Fig. S1a). The obtained diagrams revealed a frequency peak on the lower arm of chromosome four, which contained a SNP leading to a premature stop codon (Q255*) in XLG2 (EXTRA-LARGE G-PROTEIN 2, AT4G34390). Sequencing of $X L G 2$ in les 2 revealed an amino acid exchange (E293K) in the same protein. Both polymorphisms were confirmed as the causative mutations by complementation (Fig. S1c).

\section{Mutant analyses}

The following previously characterized mutants were analysed and crossed with cerk1-4: agb1-2 (Ullah et al., 2003), gpa1-3 (SALK 066823) (Jones et al., 2003), agg1-1 agg2-1 (FLAG 197F06, SALK 010956) (Trusov et al., 2007), xlg1-2 (SALK 119657) (Maruta et al., 2015), xlg2-1 (SALK 062645) (Ding et al., 2008), xlg3-4 (SALK 107656) (Yu et al., 2018), bak1-4 (SALK 116202) (Kemmerling et al., 2007), bak1-5 (Schwessinger et al., 2011), sobir1-12 (SALK_050715) (Leslie et al., 2010), sobir1-14 (GABI_643F07) (Barghahn et al., 2021), rbohD, rbohF, rbohD rbohF (Torres et al., 2002), pub2-1 (SALK_086656) (Wang et al., 2017), pub4-3 (SAIL_859_H05) (Wang et al., 2013).xlg1-2, $x \lg 2-1$ and $x \lg 3-4$ were used to produce double and triple mutants.

\section{Quantitative RT-PCR and ROS-burst assays}

Quantitative RT-PCR was performed as described previously (Petutschnig et al., 2014). For ROS burst assays, $4 \mathrm{~mm}$ leaf discs were cut out and floated in water in a white 96-well plate for at least $4 \mathrm{~h}$. Then the water was replaced with a solution containing $1 \mu \mathrm{g} / \mathrm{ml}$ horse radish peroxidase

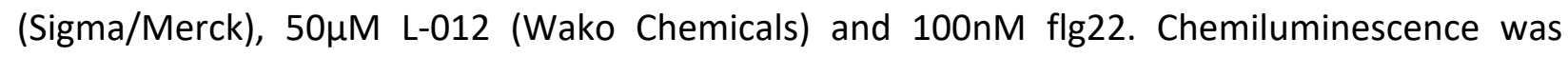
immediately recorded using a Tecan Infinite M200 plate reader. Statistical significance was tested with unpaired, two-tailed t-tests.

\section{Protein Work}

Protein extraction from Arabidopsis leaves and Western blotting were performed according to previously published protocols (Petutschnig et al., 2010). The antibodies used in Western blots 
were anti-GFP (Chromotek), anti-FLAG M2 (Sigma), anti-CERK1 (Petutschnig et al., 2010), antiGPA1 (Agrisera), anti-AGB1 (Agrisera) and anti-XLG2, a custom polyclonal antibody raised against the first 200 amino acids of XLG2 (Agrisera). Western Blot Signal Enhancer (Pierce / Thermo Fisher Scientific) was used for development with GFP and XLG2 antibodies. For GFP pull-downs, standard protein extracts were prepared (Petutschnig et al., 2010) and the target protein was isolated with either Chromotek GFP trap beads (mass spectrometry experiments) or Nanotag GFP selector beads (Co-IP experiments). Protein extracts were mixed with $\alpha$ GFP nanobody beads at a ratio of approximately $0.2-0.5 \mathrm{mg}$ total protein / $\mu \mathrm{l}$ bead slurry and incubated at $4{ }^{\circ} \mathrm{C}$ on a rotating wheel overnight. The next day, the beads were pelleted by gentle centrifugation at $1000 \mathrm{x} g$ or slower. The supernatant was discarded and the beads were washed 2-3 times with extraction buffer (Petutschnig et al., 2010) and 2-3 times with TBS-T. Bound proteins were released by boiling beads in $1 x$ SDS loading dye or beads were directly used for trypsin digestion.

\section{Microscopy}

Confocal microscopy was performed on a Leica TCS SP8 Falcon system equipped with HyD SMD detectors, a pulsed white light laser and the LASX 3.5.5 software. Venus fluorescent protein was excited at $514 \mathrm{~nm}$ and fluorescence was detected between 525-560nm. Since $p X L G 2-$ Venus-XLG2 and derivatives are weakly expressed, the accumulation mode was used in some experiments. A fluorescence lifetime gate was set between $0.4-6 n$ s to exclude chloroplast autofluorescence signals from images. Excitation and detection wavelengths for subcellular marker proteins mKate2-Lti6b and mTurquoise2-N7 (Ghareeb et al., 2016) were 594nm/600-641nm and $458 \mathrm{~nm} / 462-485 \mathrm{~nm}$ respectively. Stitched images were recorded and assembled with the LASX Navigator module. Z-stacks were exported as maximum projections and brightness/contrast was adjusted either with Adobe Photoshop CS5 or ImageJ (Fiji distribution).

\section{RESULTS}

\section{A suppressor screen identifies XLG2 as an essential component of the cerk1-4 cell death} pathway

In order to identify molecular components involved in the establishment of CERK1-4-dependent hyperimmunity, we performed a genetic suppressor screen. For this, we infected an EMSmutagenized population of cerk1-4 with powdery mildews and looked for plants with wild typelike interaction phenotypes. Two recessive suppressor mutations fully inhibited the development of dysregulated cell death upon inoculation with the incompatible powdery mildew fungus Blumeria graminis f. sp. hordei (Bgh) (Fig. 1a) and the compatible Erysiphe cruciferarum (Fig. 1b). Therefore, they were named lesion suppressor 1 and 2 (les1 and les2). Neither one of the mutations led to any obvious developmental changes in non-inoculated plants (Fig. 1c). Bghinduced PATHOGENESIS RELATED1 (PR1) expression, which is increased in cerk1-4, was reduced to levels similar to the wild type in the les1 and les 2 mutants (Fig. 1d). 
We identified the les1 mutation using a mapping-by-sequencing approach (Hartwig et al., 2012). Single nucleotide polymorphism (SNP) linkage analysis located the les1 mutation at the lower arm of chromosome 4 (Fig. S1a), with a mutation introducing a premature stop codon (Q255*) in XLG2 (Fig. 1e) being the most promising candidate. Interestingly, we found that our second suppressor mutant, les2, also harbours a mutation in the XLG2 gene, which results in a glutamic acid to lysine exchange (E293K) within a highly conserved region of the XLG2 N-terminal domain (Fig. 1e). Consequently, we transformed both mutants with a construct containing the wild type $X L G 2$ promoter and coding region, and found that the cerk1-4 cell death response to powdery mildew infection was restored in les1 as well as les2 (Fig. S1b and c). Together, these complementation analyses suggest that cerk1-4-associated hyperimmunity requires functional XLG2. Since both suppressor mutations compromise XLG2, we renamed the suppressor loci in les 1 and les 2 to $x \lg 2-2$ and $x \lg 2-3$, respectively.

\section{Mutations in G $\alpha$ and G $\beta$ subunits AGB1 and AGG1 partially suppress the cerk1-4 phenotype}

To investigate the role of other Arabidopsis heterotrimeric G-proteins in cerk1-4 cell death control, we crossed cerk1-4 with mutants of canonical $G \alpha, G \beta$ and $G \gamma$ subunits as well as all three XLGs. The resulting double mutants were analysed for their reaction to $B g h$. As expected, the xIg2-1 T-DNA insertion fully suppressed the cerk1-4 cell death response and restored expression of the SA marker PR1 to wild type levels (Fig. 2a,b). In contrast, mutations in GPA1, XLG1 and XLG3 did not suppress cerk1-4. Notably, both agb1-2 cerk1-4 and agg1-1 cerk1-4 double mutants showed an intermediate phenotype concerning cell death formation as well as PR1 expression (Fig. 2a,b). In agg1-1 cerk1-4, this might be due to functional redundancy between AGG1 and AGG2, since generation of a cerk1-4 agg1-1 agg2-1 triple mutant failed because of genetic linkage between CERK1 (At3g21630) and AGG2 (At3g22942). AGB1, however, is a single copy gene in Arabidopsis. Thus, we performed Western blotting with specific antibodies to test if CERK1 or XLG2 abundance is reduced in the G-protein mutants. CERK1 levels in these mutants were comparable to wild type (Fig. 2c), but interestingly, XLG2 had a slightly lower apparent mass in agb1 and agg1-1 agg2-1 (Fig. 2c). These findings suggest that XLG2 might require protein modifications for its function that are (partially) dependent on AGB1 and AGG1/2. GPA1 and AGB1 Western blots were included in the experiment as controls and revealed drastically reduced AGB1 abundance in agg1-1 agg2-1, probably because $\beta \gamma$-dimer formation is a prerequisite for AGB1 stability (Fig. 2c).

\section{Cell death signalling in cerk1-4 is not mediated by BAK1 or SOBIR1-containing receptor complexes}

Hyperimmunity phenotypes of the cerk1-4 mutant are associated with the extracellular part of the CERK1-4 protein (Petutschnig et al., 2014) and could potentially be perceived by a yet unknown RLK that signals through XLG2. Many of the RLKs and RLPS characterized to date use BAK1 as a co-receptor and/or SOBIR1 as an adaptor kinase (Escocard de Azevedo Manhaes et al., 2021). This encouraged us to test if the cerk1-4 cell death phenotype is dependent on BAK1 and SOBIR1. Phenotypic analysis of powdery mildew-infected cerk1-4 bak1 and cerk1-4 sobir1 double mutants clearly demonstrated that BAK1 and SOBIR1 are dispensable (Fig. 2d,e). PR1 expression 
appeared to be even higher in cerk1-4 bak1 and cerk1-4 sobir1 compared to cerk1-4 plants (Fig. 2e).

\section{The role of XLG2 in cerk1-4 signalling is independent of its function in PAMP-induced ROS generation}

XLG2 is required for full flagellin-induced ROS generation. It associates with the flagellin receptor complex and regulates NADPH oxidase activity through multiple modes of action (Liang et al., 2016; Liang et al., 2018; Wang et al., 2018). Similar to previous reports (Maruta et al., 2015), we observed a moderate reduction of flg22-induced ROS in the xlg2-1 mutant, but robustly reduced ROS generation in $x \lg 2 x \lg 3$ double and $x \lg 1 \times \lg 2 x \lg 3$ triple mutants (Fig. 3a). This redundant action of XLG proteins argues against a role for ROS generation in cerk1-4 hyperimmunity, which can be suppressed by mutations in XLG2 alone. For further analysis, we made use of a mutated

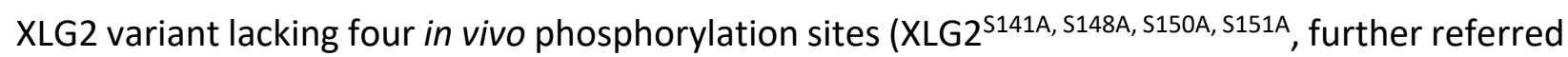
to as XLG2 ${ }^{4 S-A}$ ) required for full flg22-induced ROS burst (Liang et al., 2016). We introduced XLG2 ${ }^{4 S-A}$-FLAG into the $x / g 2-2$ cerk1-4 double mutant. Wild type XLG2-FLAG and the phosphomimic version XLG2 ${ }^{4 S-D}$-FLAG (Liang et al., 2016) were included as controls. All three XLG2-FLAG versions were similarly able to re-establish the cerk1-4 phenotype, indicating that the XLG2 phosphorylation sites governing flg22-dependent ROS regulation do not play a role here (Fig. 3b,c, Table S2). To corroborate these findings, we crossed cerk1-4 with the NADPH oxidase mutants $r b o h D$ and $r b o h F$ and the respective double mutant (Torres et al., 2002). Neither loss of RbohD or RbohF, nor the combined loss of both, suppressed the cerk1-4 cell death phenotype upon powdery mildew infection (Fig. 3d,e). Taken together, these data indicate that XLG2 exerts a function in cerk1-4 hyperimmunity that is independent of NADPH oxidase-generated ROS.

\section{Cell periphery localisation of XLG2 is required for cerk1-4 cell death dysregulation}

When transiently expressed in $N$. benthamiana leaves, XLG2 localises to the cell periphery as well as the nucleus (Chakravorty et al., 2015; Maruta et al., 2015). We could confirm this finding with Venus-tagged XLG2 (Fig. S2a) and observed the same localisation upon particle bombardment in Arabidopsis epidermal cells (Fig. S2b). Interestingly, the non-functional XLG2 ${ }^{\mathrm{E293K}}$ variant that we identified in the les2/xlg2-3 mutant almost exclusively localised to the nucleus in both transient systems (Fig. S2a,b). To study the subcellular localisation and its importance for XLG2 function in more detail, we analysed Venus-XLG2 and Venus-XLG2 ${ }^{\mathrm{E} 293 \mathrm{~K}}$ expressed under the control of the XLG2 promoter in stably transformed $x \lg 2-2$ and cerk1-4 xlg2-2 plants. In these, Venus-XLG2 localised predominantly to the cell periphery and Venus-labelled nuclei were rarely found (Fig. $4 a$, Table S3, S4), suggesting that nuclear accumulation of XLG2 observed in transient systems may be a stress response caused by Agrobacterium infiltration or particle bombardment. Again, XLG2 ${ }^{\mathrm{E} 293 \mathrm{~K}}$ showed almost exclusive localisation to nuclei (Fig. 4a, Table S3, S4). Localisation patterns were very similar in the CERK1 and cerk1-4 background. Since dysregulated cell death responses of cerk1-4 plants become apparent upon infection with powdery mildews, we investigated the subcellular behaviour of Venus-XLG2 and XLG2 $2^{\mathrm{E2} 93 \mathrm{~K}}$ after inoculation with $E$. cruciferarum. Fungal infection caused increased accumulation of Venus-XLG2 in the attacked epidermal cells, while distant cells were not affected. Moreover, nuclear Venus-XLG2 signals 
could be detected at such interaction sites (Fig. 4b, Fig. S2C). XLG2 E293K also showed increased abundance in cells challenged with E. cruciferarum, but retained its predominantly nuclear localisation (Fig. 4b, Fig. S2c). Notably, Venus-XLG2 was able to re-establish the cerk1-4 phenotype in xlg2-2 cerk1-4 plants, whereas the mutant variant Venus-XLG2 ${ }^{\mathrm{E} 293 \mathrm{~K}}$ was not (Fig. 4c, Table S4). Western blotting was employed to confirm accumulation of full-length fusion proteins in the transgenic lines (Fig. 4d). These experiments revealed that Venus-XLG2 ${ }^{\text {E293K }}$ migrated faster in SDS-PAGE than the wild type fusion protein, which will be discussed in more detail further below.

Since the non-functional mutant variant XLG2 ${ }^{\mathrm{E} 293 \mathrm{~K}}$ accumulated predominantly in the nucleus, we speculated that the cell periphery localisation of wild type XLG2 might be essential for its role in cerk1-4 cell death signalling. To address this question, we attached nuclear localisation and export signals (NLS and NES) (Garcia et al., 2010) to the C-terminus of Venus-XLG2. Nonfunctional sequences (nls and nes) were included as controls. Venus-XLG2-NLS showed nuclear localisation without pathogen challenge, but still had considerable signals at the cell periphery. Importantly, Venus-XLG2-NES was found only at the cell periphery in unchallenged tissues and did not show the typical stained nuclei in powdery mildew infected cells (Fig. 5a). All variants accumulated to similar protein levels and were able to complement xlg2-2 cerk1-4 (Fig. 5b,c, Table S4). The data suggest that indeed the periphery-localised fraction of the XLG2 protein pool promotes cerk1-4 dependent cell death and that nuclear localisation is dispensable for this process.

\section{Intrinsic features of the N-terminal domain control XLG2 subcellular localisation and cerk1-4} cell death signalling

In order to analyse the regulation of XLG2 subcellular localisation, we mutated an internal NLS (nls426) and NES (nes387) within the XLG2 N-terminal domain (Fig. 1e) based on a study by Chakravorty et al. (2015). Stable transgenic expression from the XLG2 promoter showed that Venus-XLG2 ${ }^{\text {ns426 }}$ localised to the cell periphery, had wild-type like migration properties in Western blots and could complement $x \lg 2-2$ cerk1-4. In contrast, Venus-XLG2 ${ }^{\text {nes} 387}$ was exclusively found in the nucleus, migrated faster in SDS-PAGE and was non-functional in cerk1-4 cell death signalling (Fig. 5a,b,d,e, Table S4). Taken together, the data corroborated that XLG2's specific role in cerk1-4 mutants is fulfilled at the cell periphery, and indicated that subcellular localisation of XLG2 is determined by sequences within the $\mathrm{N}$-terminal domain of the protein. $\mathrm{N}$-terminal domains of XLG proteins contain highly conserved cysteine rich regions with four invariant CxxC motifs (Fig. 1e), which are possible zinc finger domains (Lee \& Assmann, 1999). Mutation of one (C214/217A and C254/257A) or two (C229/232/237/240A) CxxC motifs (Fig.1e) resulted in non-functional Venus-XLG2 fusion proteins that resembled Venus-XLG2 ${ }^{\mathrm{E} 293 \mathrm{~K}}$ and $X L G 2^{\text {nes387 }}$ in confocal analyses and Western blots (Fig. S3a-d, Table S4). Thus, correct localisation of XLG2 also requires structural integrity of the cysteine rich region.

XLG proteins harbour a $G \alpha$ domain and weak GTP binding and GTPase activity have been demonstrated for XLG2 in vitro (Heo et al., 2012; Lou et al., 2020). To investigate if XLG2 GTPase activity plays any role in formation of the cerk1-4 cell death phenotype, we mutated its GTP binding site (T476N) as described previously (Heo et al., 2012; Maruta et al., 2021) (Fig. 1e). In 
addition, we introduced a mutation that could potentially affect GTPase activity (R673L), since a mutation in this position renders GPA1 inactive (Okamoto et al., 2001; Ullah et al., 2003)(Fig. 1e). Subcellular localisation and running behaviour in Western blots were unaffected in XLG2 ${ }^{\top 476 \mathrm{~N}}$ as well as XLG2 ${ }^{\mathrm{R} 673 \mathrm{~L}}$ and both mutant proteins were able to complement $x$ lg2-2 cerk1-4 (Fig. S4, Table S4). This indicates that GTP-binding and hydrolysis are irrelevant for XLG2 positioning and activity in cerk1-4 cell death signalling.

\section{G $\beta Y$ modulates protein modifications and subcellular localisation of XLG2}

Notably, the SDS-PAGE mobility shift of Venus-XLG2 ${ }^{\text {E293K }}$ (Fig. 4d), XLG2 ${ }^{\text {nes387 }}$ (Fig. 5d,e) and the cysteine rich region mutants (Fig. S3c,d) resembled the behaviour of wild type XLG2 in agb1 and agg1 agg2 mutants (Fig. 2c). However, direct comparison of xlg2-3 (containing untagged $\left.\mathrm{XLG} 2^{\mathrm{E} 293 \mathrm{~K}}\right), a g b 1$ and $a g g 1$ agg 2 showed that the XLG2 band shift in $x / g 2-3$ is more pronounced than in the GBY mutants (Fig. 6a). We speculated that XLG2 might carry post-translational modifications, which are moderately reduced in agb1 and agg1 agg2, but more strongly affected or missing in XLG2 ${ }^{\mathrm{E2} 93 \mathrm{~K}}$. To investigate this hypothesis, we transformed agb1-2 mutants with pXLG2-Venus-XLG2 (WT) as well as $p X L G 2$-Venus-XLG2 ${ }^{E 293 K}$ (Table S5). Western blots showed that Venus-XLG2 migrated at a lower apparent mass in the AGB1-deficient background (Fig. 6b). Venus-XLG2 ${ }^{\mathrm{E293K}}$ however showed no such mobility shift (Fig. 6c), suggesting that the same type of modification is affected in agb1-2 and the XLG2 ${ }^{\mathrm{E} 293 \mathrm{~K}}$ mutant. In agreement with this notion, Venus-XLG2 localised to both, nucleus and cell periphery in unchallenged agb1-2 plants, while Venus-XLG2 ${ }^{\mathrm{E293K}}$ localisation was not affected (Fig. 6d). XLG2 is known to interact with the GßY dimer (Zhu et al., 2009; Chakravorty et al., 2015; Maruta et al., 2015). However, this interaction capacity was strongly impaired (with and without PAMP treatment) in the XLG2 ${ }^{\mathrm{E2} 93 \mathrm{~K}}$ variant (Fig. $6 e)$. These data favour a model where direct interaction of XLG2 with $G \beta \gamma$ mediates full posttranslational XLG2 modification and contributes to proper XLG2 subcellular localisation.

\section{Phosphorylation in the N-terminal region of XLG2 is not essential for cerk1-4 cell death signalling}

Since XLG2 is heavily phosphorylated in the N-terminal domain (Liang et al., 2016; Chakravorty \& Assmann, 2018) we purified Venus-XLG2 and Venus-XLG2 ${ }^{\mathrm{E293K}}$ from transgenic Arabidopsis plants via the fluorescence tag and performed phosphatase assays. Upon de-phosphorylation, both XLG2 versions showed the same running behaviour in Western blot analyses (Fig. 7a), indicating that Venus-XLG2 ${ }^{\mathrm{E} 293 \mathrm{~K}}$ indeed has a phosphorylation defect. For further analysis, we carried out phosphoproteomics studies on the two fusion proteins, each isolated from three independent Arabidopsis lines. Phosphopeptides were clustered into 5 non-overlapping regions (Fig. 1e, Fig. 7b), and subjected to targeted selected ion monitoring (tSIM) to quantify phosphorylation levels. These analyses revealed that XLG2 $2^{\mathrm{E} 293 \mathrm{~K}}$ showed drastically reduced phosphorylation near the $\mathrm{N}$ terminus (aa 1-79, Fig. 7b). Interestingly, phosphorylation of sites reported to regulate XLG2 function in PAMP-induced ROS generation (aa 141-156) (Liang et al., 2016) was increased in XLG2 ${ }^{\text {E293K }}$, while more distant sites (aa 184-194) were not affected (Fig. 7b). We had already shown that phosphorylation within the aa 141-156 region does not play a role in cerk1-4 signalling (Fig. $3 \mathrm{~b}, \mathrm{c}$ ). In order to assess the contribution of XLG2 N-terminal phosphorylation, we 
mutated all 27 serine and threonine residues in the aa 1-79 segment to alanines (XLG2 $\left.{ }^{275 / T-A}\right)$. XLG2 has a serine rich stretch (SGS 7 at amino acid positions 124-130, Fig. 1e), which is not amenable to mass spectrometry analysis, but may still be important for XLG2 function. This was also mutated (XLG2 ${ }^{8 \mathrm{~S}-\mathrm{A}}$ ) and both constructs were transformed into $x / g 2-2$ cerk1-4. The expressed fusion proteins showed reduced apparent masses compared to the wild type Venus-XLG2 version (Fig. 7c). Venus-XLG2 ${ }^{27 S / T-A}$ displayed a very similar motility in SDS-PAGE to Venus-XLG2 ${ }^{\text {E293K }}$ (Fig. $7 d)$. However, both Venus-XLG2 ${ }^{8 S-A}$ and Venus-XLG2 ${ }^{27 S / T-A}$ showed a cell periphery localisation comparable to the wild type version (Fig. 7e) and complemented the $x / g 2-2$ mutation (Fig. $7 f$ ). These data suggest that the mobility shift of $X L G 2^{\mathrm{E} 293 \mathrm{~K}}$ is due to reduced phosphorylation, but this is not the cause of its altered localisation and inability to signal in the cerk1-4 pathway.

\section{XLG2 functions in cerk1-4 cell death signalling together with the E3 ubiquitin ligase PUB2}

All three Arabidopsis XLGs were reported to interact with the E3 ligases PLANT U-BOX 2 (PUB2) and PUB4. Moreover, $x \lg 1 \times \lg 2 \times \lg 3$ triple and pub2 pub4 double mutants share similar developmental and hormone response defects (Wang et al., 2017). Indeed, in our phosphoproteomics analyses, PUB4 and PUB2 were robustly detected as interactors of VenusXLG2 (WT) as well as Venus-XLG2 ${ }^{\mathrm{E2} 93 \mathrm{~K}}$ (Fig. 8a). Immunoblot analysis of pub4 and pub2 mutants with a XLG2-specific antibody did not reveal any obvious size differences of XLG2, suggesting that PUB4 and PUB2 do not mediate modification of XLG2 (Fig. 8b). To investigate if PUB4 and PUB2 play a role in the formation of the cerk1-4 cell death phenotype, the respective mutants were crossed with cerk1-4 and inoculated with Bgh. These experiments showed clearly reduced cell death formation in pub2-1 cerk1-4 compared to cerk1-4 alone (Fig. 8c). Similarly, Bgh-induced PR1 accumulation was lower in pub2-1 cerk1-4 than in cerk1-4 (Fig. 8d). The pub4-3 mutation however was not able to suppress the cerk1-4 phenotype (Fig. 8c,d), suggesting that PUB2 is the predominant interactor in this process.

\section{DISCUSSION}

In this study, we show that loss of function mutations in the heterotrimeric G-protein $\alpha$-subunit XLG2 suppress the cerk1-4 phenotype. cerk1-4 plants harbour a single amino acid exchange in the extracellular domain of CERK1 and display excessive cell death and SA accumulation after infection with powdery mildews. Previous analyses showed that in contrast to chitin signalling, this phenotype is independent of CERK1 kinase activity, but correlates with an altered CERK1 shedding status (Petutschnig et al., 2014). This suggests a novel pathway, where CERK1-4 generates a cell death signal, but is not itself the signal transducing kinase. Identification of $x / g 2$ mutations as suppressors confirms the idea that cerk1-4-associated cell death involves the generation of a specific molecular signal and active signal transduction by the plant.

In transient expression systems, XLG2 localises to the nucleus, cytosol and plasma membrane (Chakravorty et al., 2015; Maruta et al., 2015), while XLG2 expressed from its native promoter is found predominantly at the cell periphery in stable transgenic Arabidopsis plants. This implies 
that nuclear localisation of XLG2 reflects a stress response, triggered for example by Agrobacterium infiltration. Indeed, when Arabidopsis plants were inoculated with spores of the powdery mildew E. cruciferarum, (which elicits the runaway cell death phenotype in cerk1-4), attacked cells showed nuclear XLG2 signals along with overall increased XLG2 levels. From the cerk1-4 suppressor screen, we isolated a non-functional XLG2 variant with an amino acid exchange (E293K) in the N-terminal domain, which showed almost exclusive nuclear localisation. To investigate the relationship between XLG2 subcellular localisation and function in the cerk1-4 pathway, we generated XLG2 versions with altered subcellular localisation by appending additional NES and NLS signals or mutating endogenous NES and NLS sequences (XLG2 ${ }^{\text {nes387 }}$ and $X L G 2^{\text {nls426 }}$, respectively). Experiments with these variants revealed that XLG2 localisation is determined by the $\mathrm{N}$-terminal domain and that XLG2 performs its role in cerk1-4-associated cell death signalling at the cell periphery. These results suggest that a CERK1-4-derived signal is perceived by a PM-resident sensor, as outlined further below. The role of XLG2 in the nucleus upon fungal infection is currently unclear. (Heo et al., 2012) reported that XLG2 interacts with the DNA binding protein RELATED TO VERNALISATION 1 (RTV1) in the nucleus. RTV1 promotes flowering (Heo et al., 2012), but there is no evidence for any involvement in plant immunity to date.

The N-terminal domain of XLG2 contains a highly conserved cysteine-rich region with four invariant CxxC motifs. It is reminiscent of a zinc finger domain and therefore has been speculated to possess DNA binding activity (Lee \& Assmann, 1999; Ding et al., 2008; Heo et al., 2012). If the cysteine rich region specifically mediated nuclear functions of XLG2 such as DNA binding, mutation of this segment should not affect cerk1-4 signalling. However, disruption of CxxC motifs resulted in non-functional XLG2 proteins with nuclear localisation. These resembled XLG2 ${ }^{\mathrm{E} 293 \mathrm{~K}}$

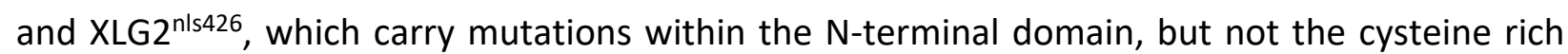
region. Taken together the results suggest that the $\mathrm{CxxC}$ motifs, as well as other conserved regions, are important for the integrity of the entire $\mathrm{N}$-terminal domain, which is in turn essential for XLG2 function.

XLG2 has weak GTP binding / GTPase activity in vitro (Heo et al., 2012; Lou et al., 2020) but it is currently not entirely clear whether this is relevant in planta. (Liang et al., 2018) reported that XLG2 variants with deleted guanine nucleotide-binding motifs display stabilized interaction with AGB1. Analysis of $x \lg 2 x \lg 3$ plants expressing the XLG2 deletion variants suggested that GTP binding contributed to a full flagellin-induced ROS burst and resistance to virulent Pseudomonas bacteria (Liang et al., 2018). On the other hand, a recent study showed that an XLG2 variant which is unable to bind GTP ( $X L G 2^{\top 476 N}$ ) had normal interaction with $G \beta \gamma$ and was able to complement PAMP-induced ROS generation and resistance to Pseudomonas in $x / g 2$ xlg 3 plants (Maruta et al., 2021). Our data indicate that the nucleotide-depleted XLG2 ${ }^{\top 476 N}$ (Heo et al., 2012; Maruta et al., 2021) and the potentially GTPase-dead variant XLG2 ${ }^{\mathrm{R} 673 \mathrm{~L}}$ are functional in cerk1-4 signalling. These findings support the idea that XLG2 can fulfil at least some of its functions independently of nucleotide exchange.

XLG2 physically interacts with $A G B 1$ and AGG1/AGG2 at the plasma membrane (Chakravorty et al., 2015; Maruta et al., 2015) and the resulting heterotrimeric complex signals not only 
downstream of the flagellin receptor (Liang et al., 2016; Liang et al., 2018; Wang et al., 2018), but also mediates constitutive immune responses in the bir1 mutant (Liu et al., 2013; Maruta et al., 2015). This led us to test if AGB1 and AGG1 contribute to powdery mildew-induced excessive cell death in cerk1-4. We found that cerk1-4 agb1-2 and cerk1-4 agg1-1 had a partially suppressed cell death phenotype with weaker, but not abolished macroscopic lesions. In the case of cerk1-4 agg1-1, this could be due to an intact AGG2 protein, which we could not address in cerk1-4 agg11 agg2-1 mutants because of genetic linkage between AGG2 and CERK1. In contrast, AGB1 does not have any functionally redundant homologs in Arabidopsis. Consequently, the results indicate that AGB1 enhances cerk1-4 cell death signalling, but is not essential for the process. An explanation for this outcome could be that AGB1 itself does not relay any signals, but affects the status of XLG2. Indeed, Western blot analyses suggested altered phosphorylation of XLG2 in the agb1-2 and agg1 agg2 background. However, since several different multiple phosphorylation mutants of XLG2 still function normally in cerk1-4 signalling, it seems most likely that the changed subcellular localisation of XLG2 in agb1-2 is the reason for the partial cell death suppression. XLG2 is shifted towards the nucleus in agb1-2 plants, suggesting that interaction with the G $\beta \gamma$ dimer helps tether XLG2 to the plasma membrane. As overexpression of G $\beta \gamma$ can sequester XLG3 at the plasma membrane (Chakravorty et al., 2015), this seems to be a general mechanism regulating XLG localisation. If $G \beta \gamma$ is absent, less XLG2 might be available for signalling from membraneassociated receptors.

Knockout or mutation of immunity genes can lead to constitutive defense responses and one proposed explanation is guarding by nucleotide-binding leucine-rich repeat (NLR) proteins (Roux et al., 2011; Schwessinger et al., 2011). This hypothesis has recently gained new momentum by the discovery that bak1-4-associated autoimmunity is dependent on helper NLRs (Wu et al., 2020). However, the cerk1-4 cell death phenotype is conferred by the N-terminal part of the CERK1-4 protein and the kinase domain is not required (Petutschnig et al., 2014). This makes an intracellular perception system an unlikely scenario. It is conceivable that CERK1-4 generates a cell death signal in the apoplast, which could be sensed by a RLK or RLP-type receptor that interacts with the XLG2-AGB1-AGG1/AGG2 heterotrimeric G-protein complex. Many receptors characterized to date use BAK1 as a co-receptor and/or SOBIR1 as an adaptor kinase (Escocard de Azevedo Manhaes et al., 2021). Analysis of cerk1-4 double mutants with bak1 and sobir1 showed that the cerk1-4 signalling pathway does not rely on these two RLKs. Thus, the signal perception machinery triggering excessive immune responses in cerk1-4 and bir1 mutants (Liu et al., 2013; Liu et al., 2016) must be different. Interestingly, cerk1-4 bak1 and cerk1-4 sobir1 double mutants even had increased $P R 1$ expression after powdery mildew infection, suggesting that BAK1 and/or SOBIR1-containing immune complexes compete for shared downstream signalling components (such as XLG2) with the receptor system that senses CERK1-4. Competitive binding of different RLKs to XLG2 was recently reported (Maruta et al., 2021).

XLG2 has been shown in multiple studies to facilitate PAMP-induced ROS bursts together with XLG3 (Maruta et al., 2015; Liang et al., 2016; Liang et al., 2018; Maruta et al., 2021). Therefore, we investigated if the role of XLG2 in ROS control is important for the formation of the cerk1-4 
phenotype. We found that XLG2 mediates flagellin-triggered ROS production redundantly with not only XLG3, but also XLG1. Since the cerk1-4 phenotype is suppressed by $x \lg 2$ alone, this argued against an involvement of ROS in cerk1-4 cell death formation. Indeed, XLG2 variants with mutated phosphorylation sites that are compromised in ROS regulation (Liang et al., 2016) were fully functional in the cerk1-4 pathway. These findings were corroborated by the fact that $r b o h D$ and $r b o h F$ mutants were unable to suppress the cerk1-4 phenotype.

$\mathrm{XLG2}$ in agb1-2, the XLG2 ${ }^{\mathrm{E} 293 \mathrm{~K}}$ variant and all other non-functional XLG2 versions generated in this study showed faster migration in SDS-PAGE than the wild type version of the protein. Phosphatase assays indicated that the difference in apparent mass was caused by phosphorylation, therefore we quantitatively analysed phosphorylation patterns on XLG2 and $\mathrm{XLG}^{\mathrm{E} 293 \mathrm{~K}}$. Interestingly, sites required for proper ROS induction (Liang et al., 2016) were more phosphorylated in XLG2 $2^{\mathrm{E} 293 \mathrm{~K}}$ than the wild type. Liang et al. (2016) found S141, S148, S150 and S151 to be phosphorylated in flagellin-challenged cells. Therefore, it is worth noting that we found phosphorylation in this region in the absence of any PAMP treatment. Residues closer to the N-terminus (S/T 13-79) were significantly less phosphorylated in XLG2 ${ }^{\text {E293K }}$ than wild type XLG2, therefore we generated corresponding XLG2 mutation variants. Analysis of Arabidopsis lines stably expressing these constructs confirmed that the lower apparent mass of XLG2 $2^{\mathrm{E} 293 \mathrm{~K}}$ is caused by reduced phosphorylation, but also showed that this is not the reason why XLG2 $2^{\mathrm{E} 293 \mathrm{~K}}$ is non-functional. Presumably, XLG2 is not regulated by phosphorylation in the cerk1-4 pathway. $\mathrm{XLG2} 2^{\mathrm{E} 293 \mathrm{~K}}$ is unable to interact with AGB1, which can partially explain its lack of function, but it seems very likely that the E293K mutation also disrupts interaction with other proteins.

In our mass spectrometry analyses, we robustly co-purified PUB2 and PUB4 together with XLG2. Both ubiquitin E3 ligases were previously reported to interact with XLGs and function in cytokinin signalling and floral development (Wang et al., 2017). We isolated PUB2 and PUB4 with wild type XLG2 as well as the E293K variant. This suggests that they interact with XLG2 at the cell periphery and the nucleus and that the interaction may not be dependent on an intact N-terminal domain. Western blot analysis of XLG2 in pub2 and pub4 mutants did not show any apparent mass differences to the wild type background. Thus, these E3 ligases might not modify XLG2, but might be regulated by XLG2 to modify other proteins. Mainly PUB4 is required for full chitin induced ROS generation (Desaki et al., 2019; Derkacheva et al., 2020) and it is tempting to speculate that this function depends on XLG2/3. Interestingly, pub2 but not pub4 was able to partially suppress powdery mildew induced cell death in cerk1-4. It seems that both PUBs interact with XLGs in many different pathways, but there is some level of specialisation between them.

Taken together, our results show that XLG2 functions in a novel, so far uncharacterized pathway to transduce the CERK1-4-specific cell death signal at the plasma membrane. In contrast to previously described immune signalling systems that utilize XLG2, this mechanism is independent of BAK1 and SOBIR1 and not regulated by NADPH-generated ROS or XLG2 phosphorylation in the $\mathrm{N}$-terminal domain. 


\section{ACKNOWLEDGEMENTS}

547

548 We thank Jian-Min Zhou (Institute of Genetics and Developmental Biology, Chinese Academy of 549 Sciences) for providing XLG2-FLAG, XLG2 4S-A-FLAG and XLG2 4S-D-FLAG constructs. We 550 especially thank Sabine Wolfarth and Ludmilla Heck-Hrarti for technical assistance, and Kerstin 551 Schmitt and Oliver Valerius (Core Facility LCMS Protein Analytics of the Faculty of Biology and 552 Psychology and the Faculty of Forest Sciences and Forest Ecology, Georg-August University 553 Göttingen) for mass spectrometry analyses. This work was funded by the DFG grants LI 1317/105541 and INST 186/1277-1 FUGG. 

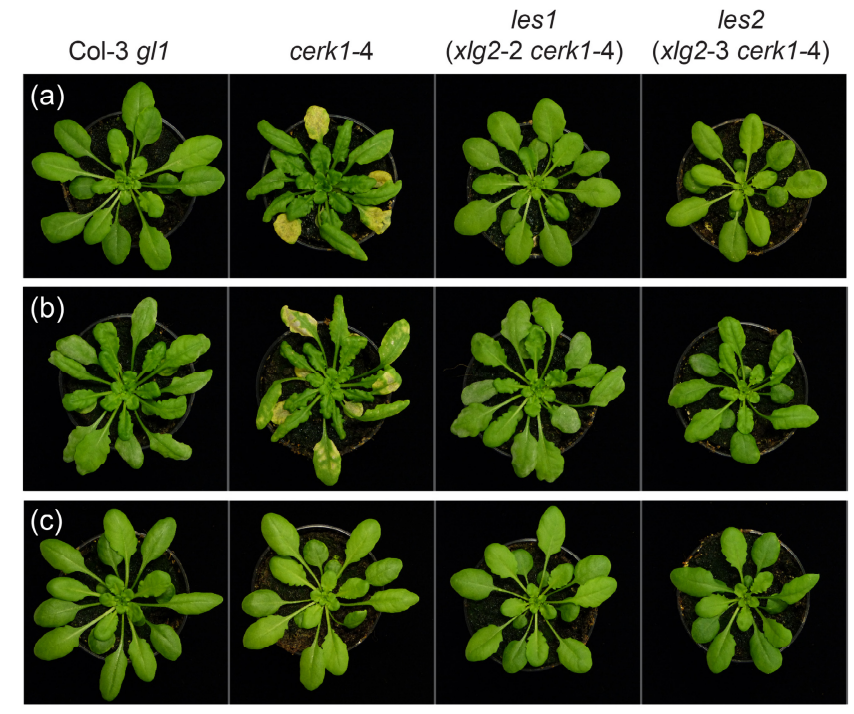

(d)

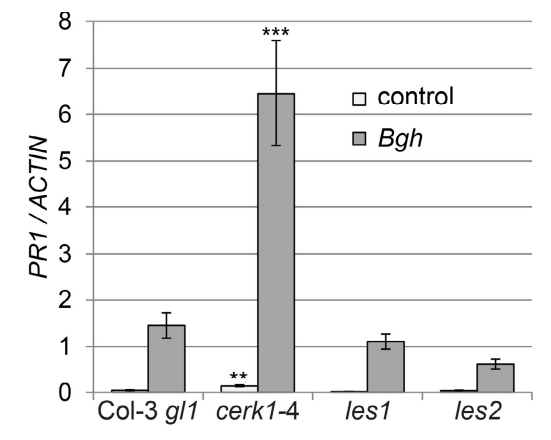

(e)

HsGa-i
GPA1
XLG1
XLG

XLG3

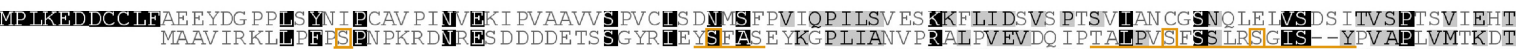
MEKKDEGESWIEMVRKMLP PGATIPEDPSE FDYSTALEYTG REPVHDI PR

HsGa-i

XLG1
XLG2
XLG3

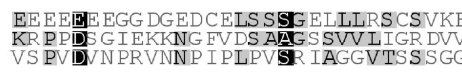

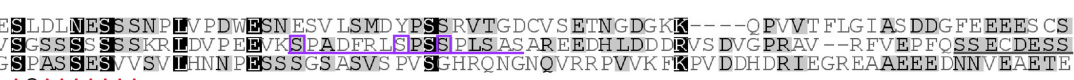
AGAAAAAAA
xIg2 8 S-A

HsGa-i
GPA1

$X L G 1$
$X L G 2$
$X L G 3$

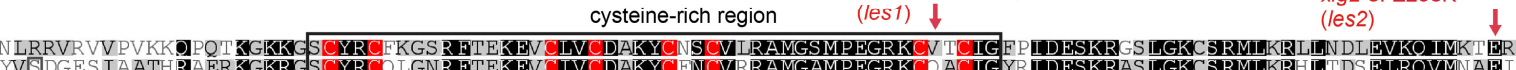

xlg2-2: Q255 stop

xlg2-3: E293K

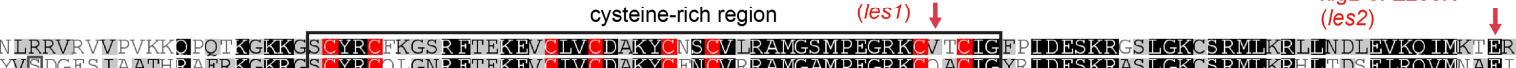

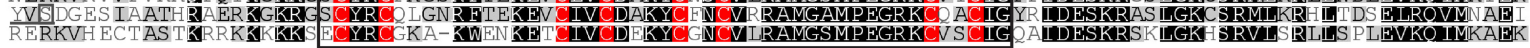

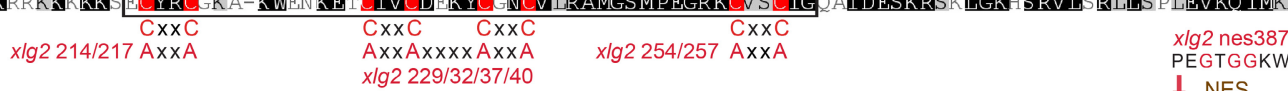

$\begin{array}{lll}H S G \alpha-i & x / g 2229 / 32 / 37 / 40 & \downarrow \text { NES } \\ \text { GPA1 } & & \end{array}$

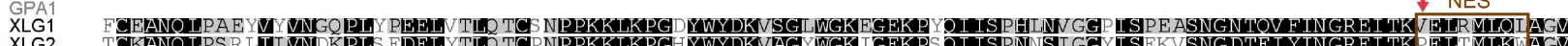

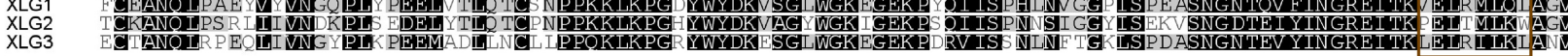
HsGa-i $x \mid g 2$ nls 426 G1 (GXXXXGKST)

$H s G \alpha-1$
GPA1

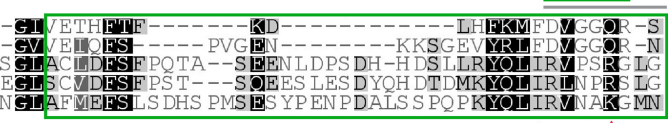

$$
\text { G4 (NKXD) }
$$
gpa1 Q222L
Xlg2 R673L

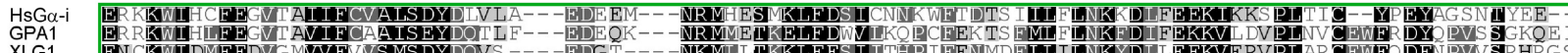

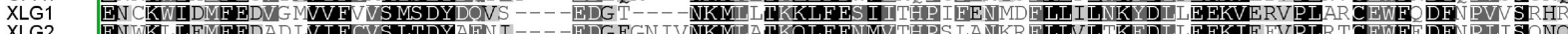

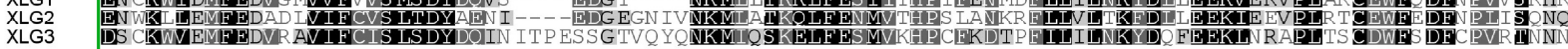

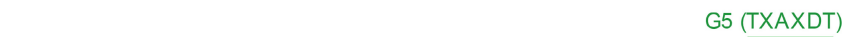


559 Figure 1: Two independent mutations in XLG2 suppress enhanced powdery mildew-induced defence responses in cerk1-4.

Representative plants of the indicated genotypes 10 days after inoculation with (a) Blumeria graminis $f$. $s p$. hordei (Bgh) or (b) Erysiphe cruciferarum. (c) Unchallenged control plants of the same age. (d): Quantitative RT-PCR analysis of $P R 1$ expression in plants infected with $B g h(5 \mathrm{dpi})$ normalized to the expression of $A C T I N$. The results represent averages of four technical replicates \pm SD. Significant differences between mutants and Col-3 g/1: ${ }^{* *} \mathrm{P}<0.01, * * * \mathrm{P}$ $<0.001$. (e) Alignment of Arabidopsis XLG proteins with GPA1 and human G $\alpha$-i. Within the GTPase domain, the helical and Ras-like domains (as determined for GPA1) are shown as blue and green boxes, respectively (Jones et al., 2011). The conserved GTPase regions G1-G5 are indicated by green lines and consensus sequences for motifs are given in brackets (Ding et al., 2008). The cysteine rich region is depicted as a black box and conserved cysteines within are highlighted in red. A functional nuclear export signal (NES) determined for XLG3 and nuclear localisation signal (NLS) determined for XLG2 (Chakravorty et al., 2015) are indicated by brown boxes. Mutations generated in this study are indicated in red. Regions within the N-terminal domain that show reduced phosphorylation in XLG2 $2^{\mathrm{E} 293 \mathrm{~K}}$ compared $^{2}$ to wild type XLG2 are underlined in orange, a region with increased phosphorylation in XLG2 $2^{\mathrm{E} 293 \mathrm{~K}}$ is underlined purple and a region with unchanged phosphorylation levels is underlined grey. Unambiguously assigned phosphorylation sites within these regions are indicated by boxes. The phosphorylation sites within the purple region were shown to be required for full flg22-induced ROS-burst (Liang et al., 2016). 


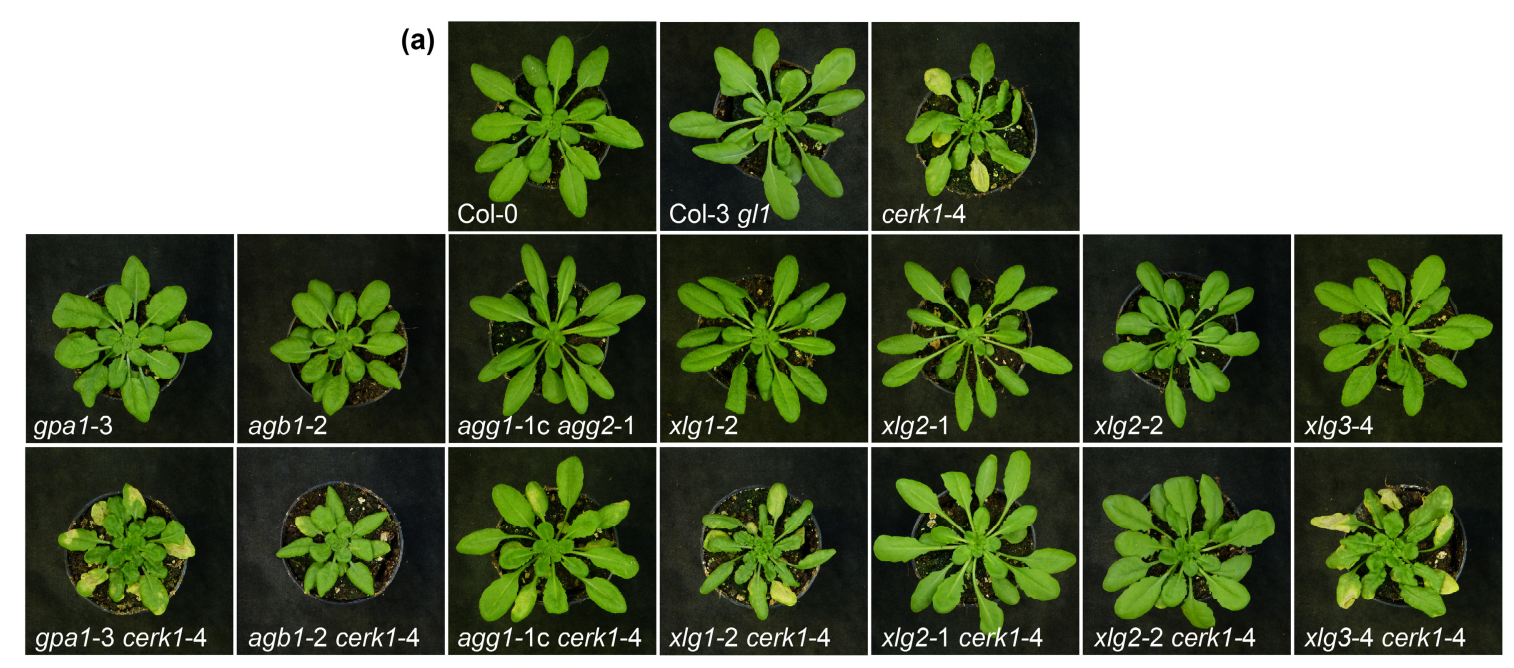

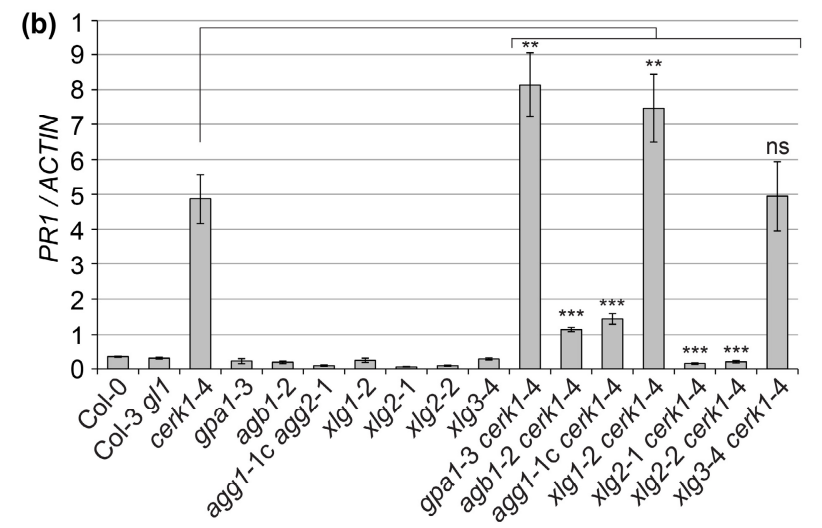

(d)
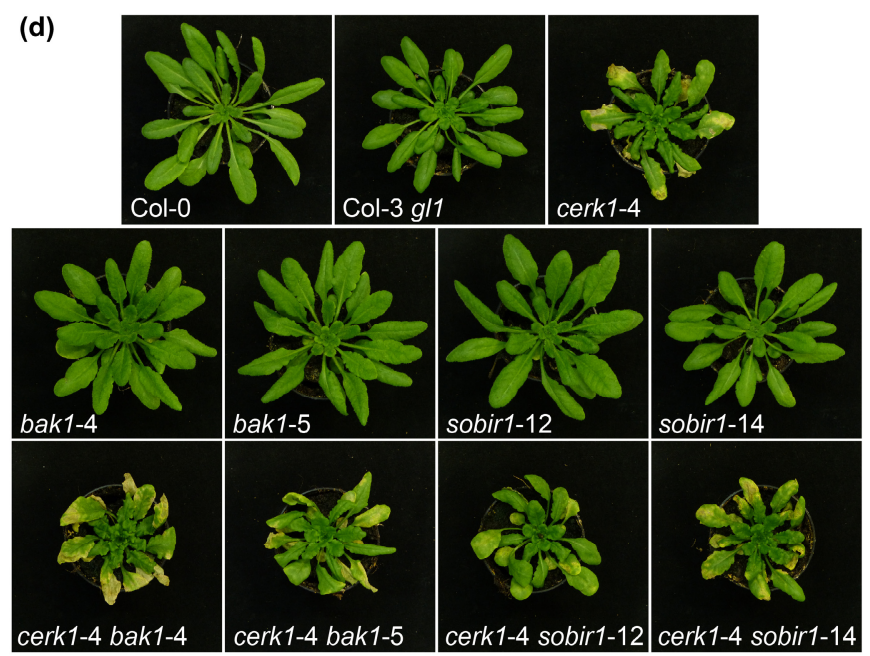

(c)

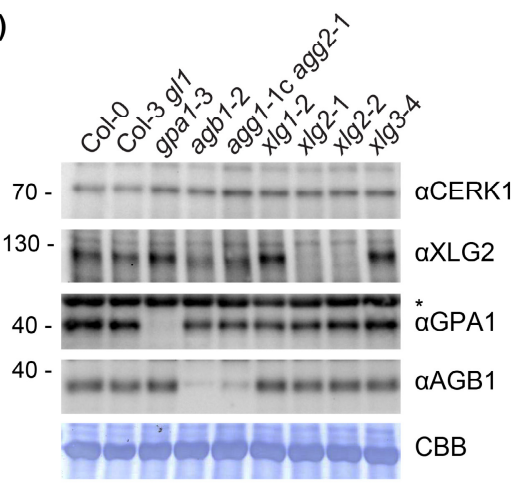

(e)

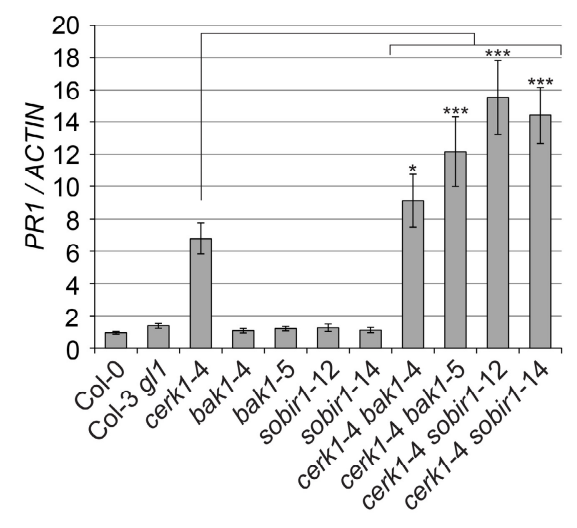

Figure 2: G-protein $\beta$ and $\gamma$ subunits, but not BAK1 and SOBIR1, are required for full development of the cerk1-4 cell death phenotype.

(a) The indicated heterotrimeric G-protein single and cerk1-4 double mutants were inoculated with Bgh and images were taken $7 \mathrm{dpi}$. (b) PR1 expression was analysed by qRT-PCR and values were normalized to the expression of ACTIN. Whole rosettes were harvested 7d after Bgh inoculation and 10 plants were pooled for each sample. (c) Gprotein mutants were analysed by Western blotting using CERK1-, GPA1-, AGB1- and XLG2-specific antibodies. * indicates unspecific band. CBB: Coomassie Brilliant Blue staining. (d) The indicated bak1 and sobir1 mutants and their crosses with cerk1-4 were inoculated with Bgh and images were taken 7dpi. (e) PR1 expression was analysed by qRT-PCR and values were normalized to the expression of ACTIN. Whole rosettes were harvested after $5 \mathrm{~d}$ and 10 plants were pooled for each sample. qRT-PCR experiments are presented as averages of four technical replicates \pm SD. Significant differences between cerk1-4 and cerk1-4 double mutants are indicated, $* \mathrm{P}<0.05, * * \mathrm{P}<0.01, * * * \mathrm{P}$ $<0.005$. 

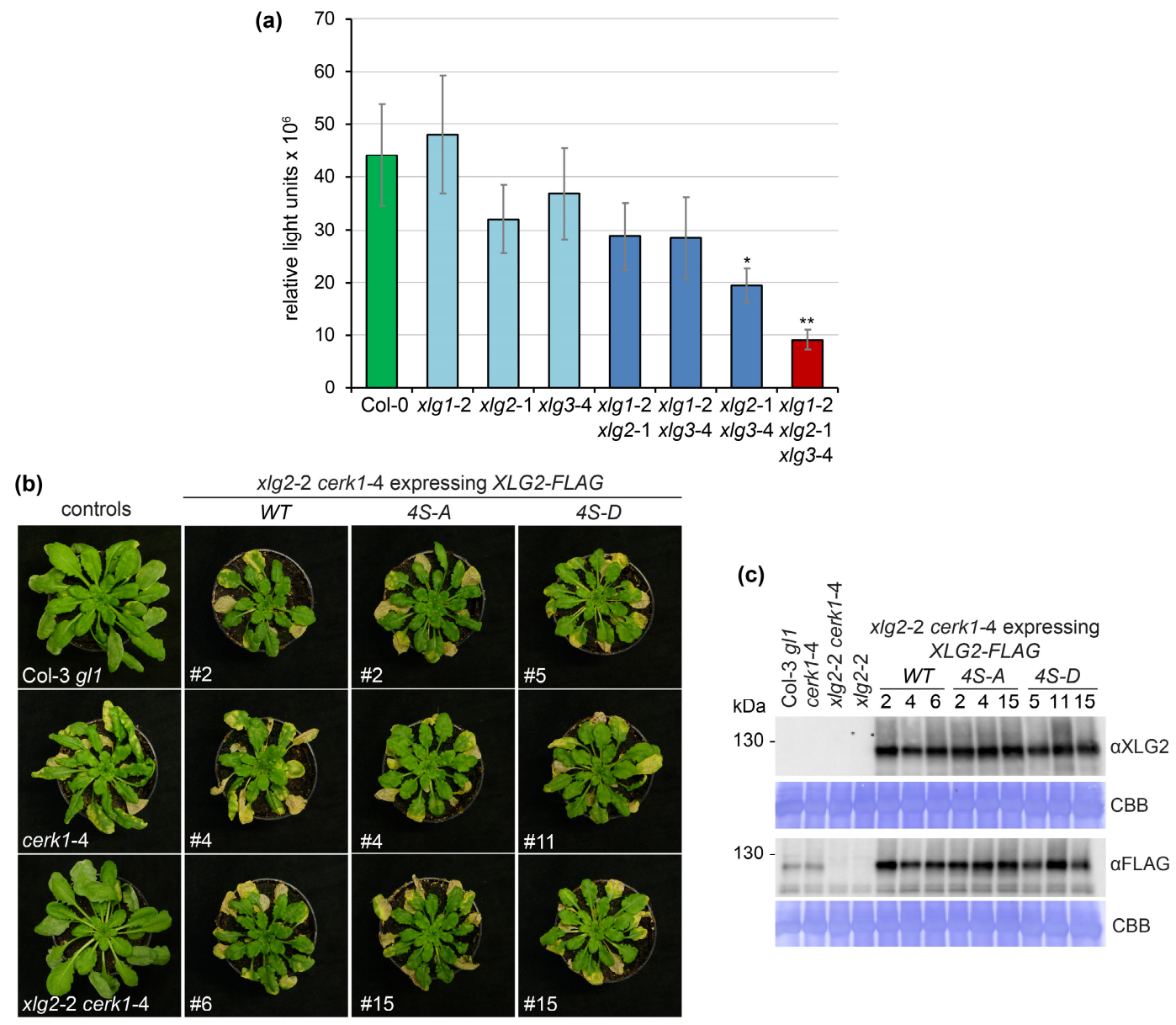

(d)
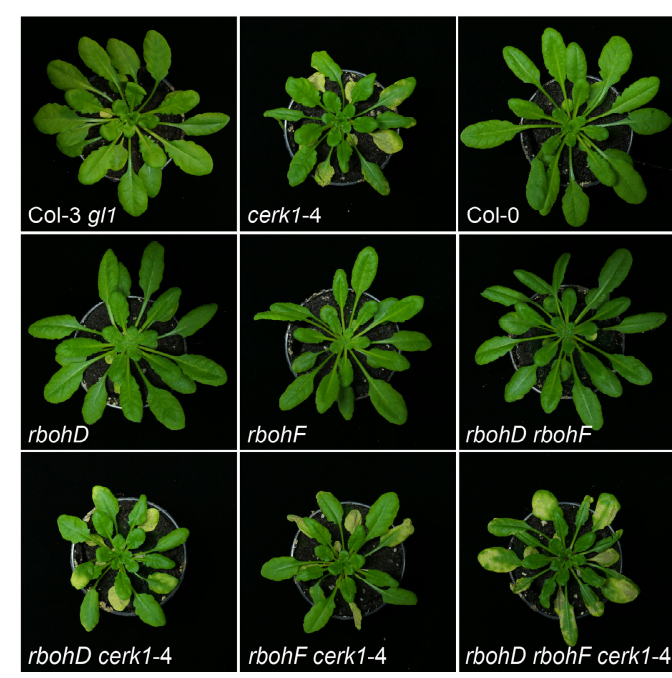

(e)

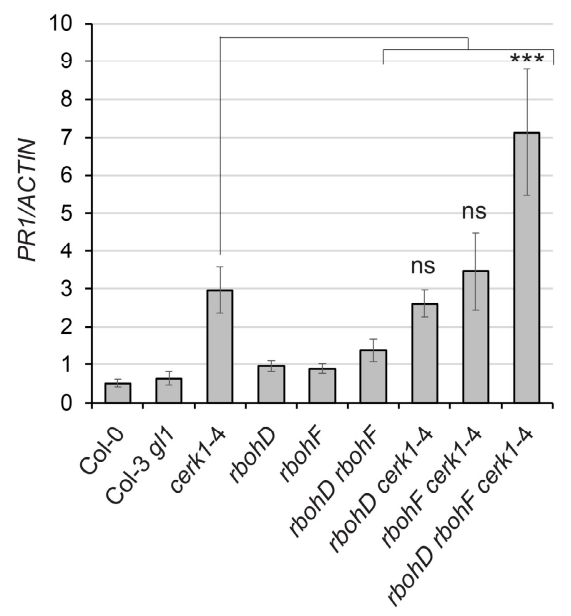

Figure 3: The cerk1-4 cell death phenotype is independent of NADPH oxidase-mediated ROS generation

(a) The indicated plant lines were treated with $100 \mathrm{nM}$ flg22 and ROS generation was recorded over 50 min. Data represent average accumulated values from 6 experiments (with 8 samples per line and experiment) \pm SEM. $* \mathrm{P}<$ $0.05,{ }^{* *} \mathrm{P}<0.01$. (b) $x / g 2-2$ cerk1-4 plants were transformed with the indicated XLG2-FLAG constructs. 10 days after inoculation with E. cruciferarum, all transgenic plants showed cell death symptoms similar to cerk1-4. Three representative transformants per construct are shown. (c) Western blots of the plants shown in (B) with FLAG- and XLG2-specific antibodies. (d, e) cerk1-4 plants were crossed with $r b o h D$ and rbohF. The resulting double and triple mutants and control plants were inoculated with $B g h$ and analysed 7 dpi. (d) Pictures of representative plants. (e) For each line, 10 whole rosettes were pooled, PR1 expression was analysed by qRT-PCR and values were normalized to the expression of ACTIN. qRT-PCR experiments are presented as averages of four technical replicates \pm SD. Significant differences between cerk1-4 and cerk1-4 crosses are indicated, ${ }^{* * *} \mathrm{P}<0.005$, (ns, not significant). 

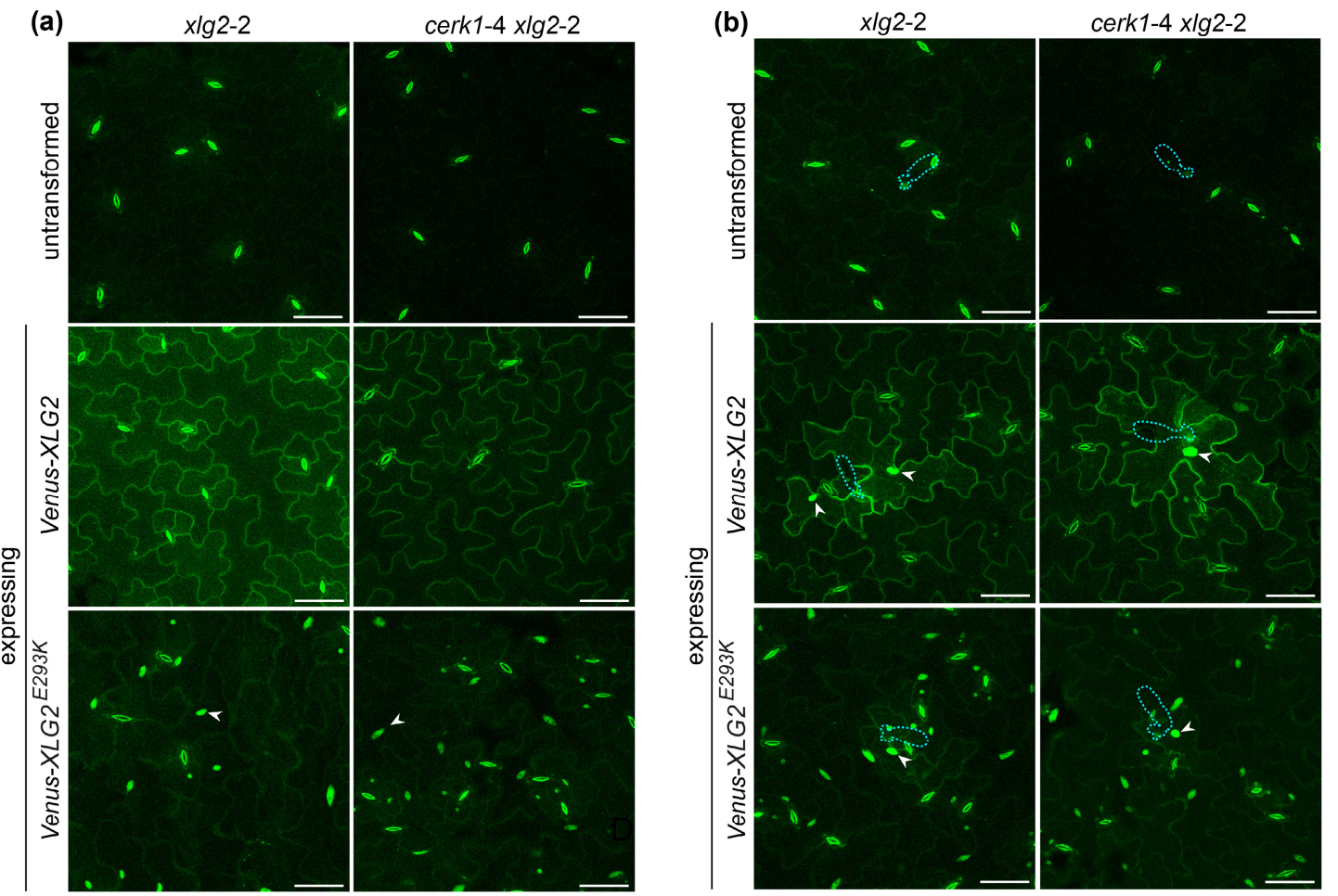

(c)

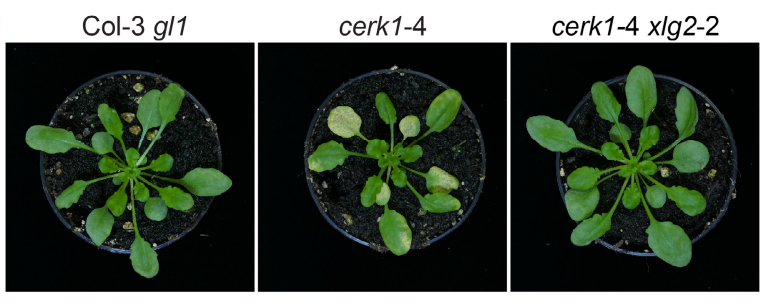

cerk1-4 xlg2-2 expressing

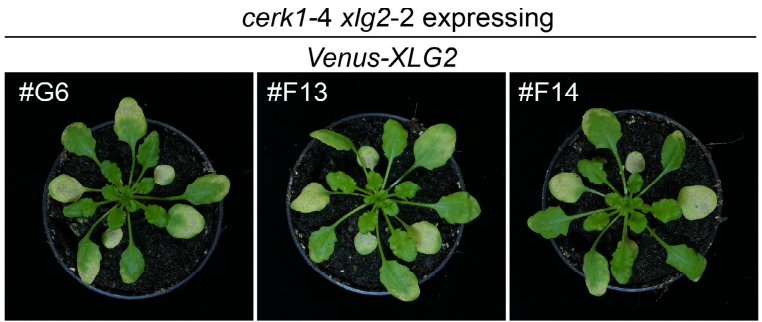

Venus-XLG2 ${ }^{E 293 K}$

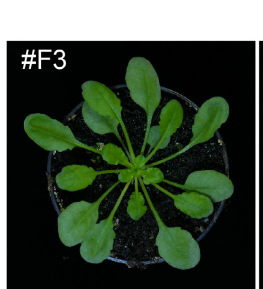
\#F17
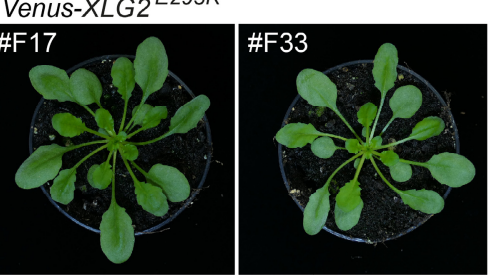

(d)

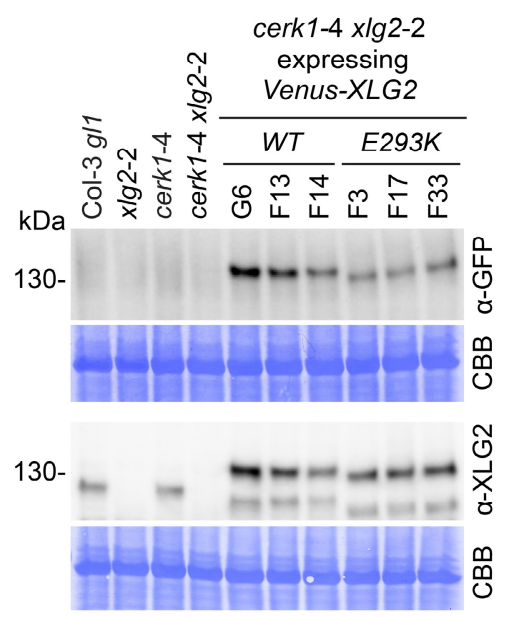

Figure 4: The E293K mutation alters subcellular localisation of XLG2 in unchallenged and powdery mildew infected Arabidopsis plants and impairs XLG2 function.

$(a, b)$ Localisation analyses of Venus-XLG2 and Venus XLG2 ${ }^{\mathrm{E293K}}$ stably expressed from the endogenous promoter in xlg2-2 and cerk1-4 x/g2-2. Untransformed control plants are included for better discernibility of stomata autofluorescence. Leaf epidermis CLSM images of (a) unchallenged plants, (b) plants 1 dpi with E. cruciferarum. Images are maximum projections of z-stacks spanning the epidermal cell layer. Positions of spores and appressoria are indicated by dashed blue outlines and example nuclei are indicated by white arrowheads. Scale bar $=50 \mu \mathrm{m}$. (c) cerk1-4 xlg2-2 plants stably expressing $p X L G 2-V e n u s-X L G 2$ or Venus-XLG2 ${ }^{E 293 K}$ as well as the indicated controls 10 dpi with E. cruciferarum. Images of three independent transformants are shown. (d) Western Blots of the transgenic pXLG2-Venus-XLG2 or Venus-XLG2 ${ }^{E 293 K}$ lines developed with XLG2 and GFP-specific antibodies. CBB = Coomassie Brilliant Blue stained membrane. 

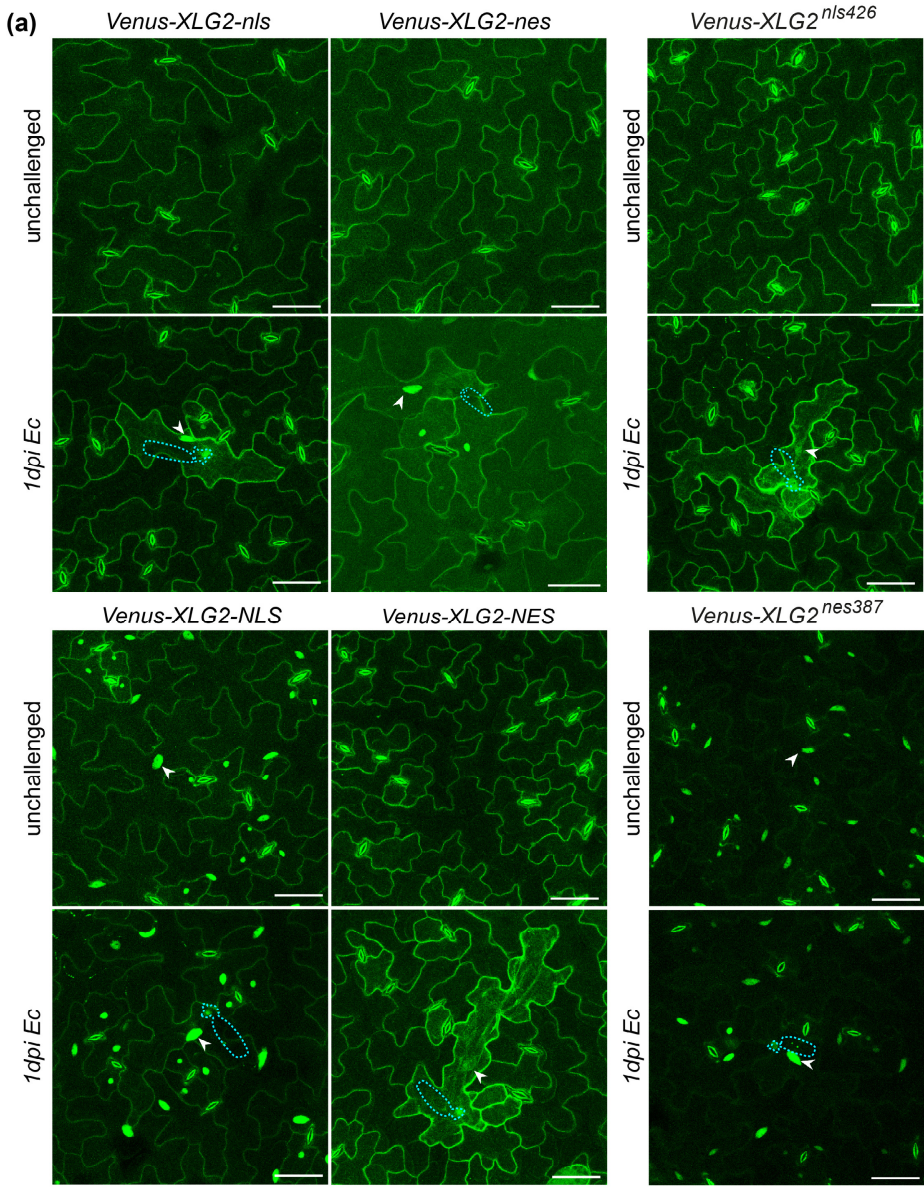

Venus-XLG2 $2^{\text {n/s } 426}$

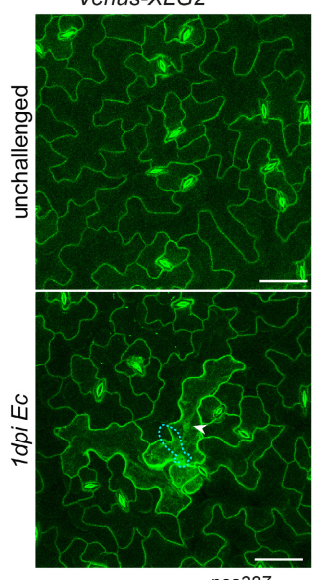

(d)

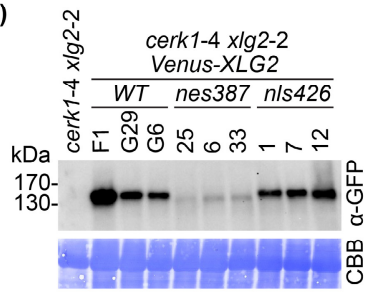

(e)

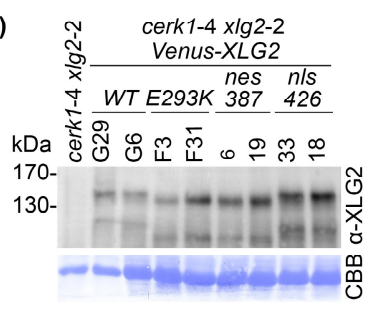

(b)
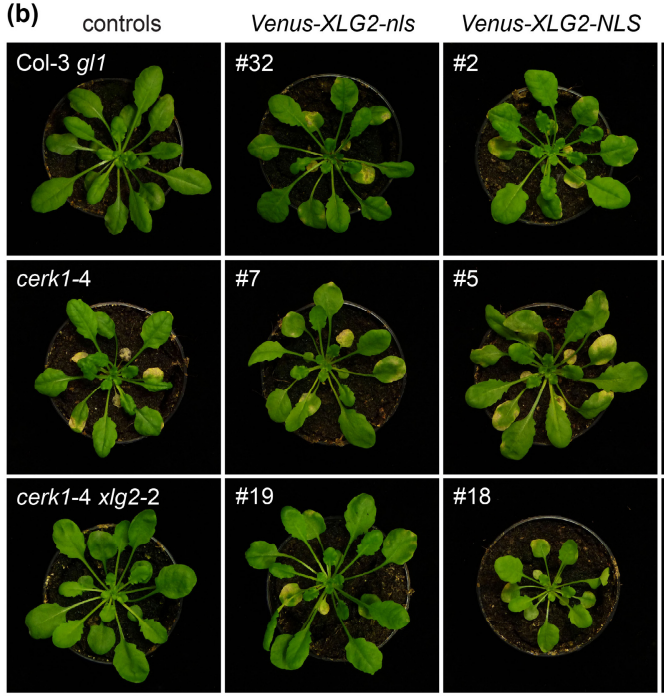
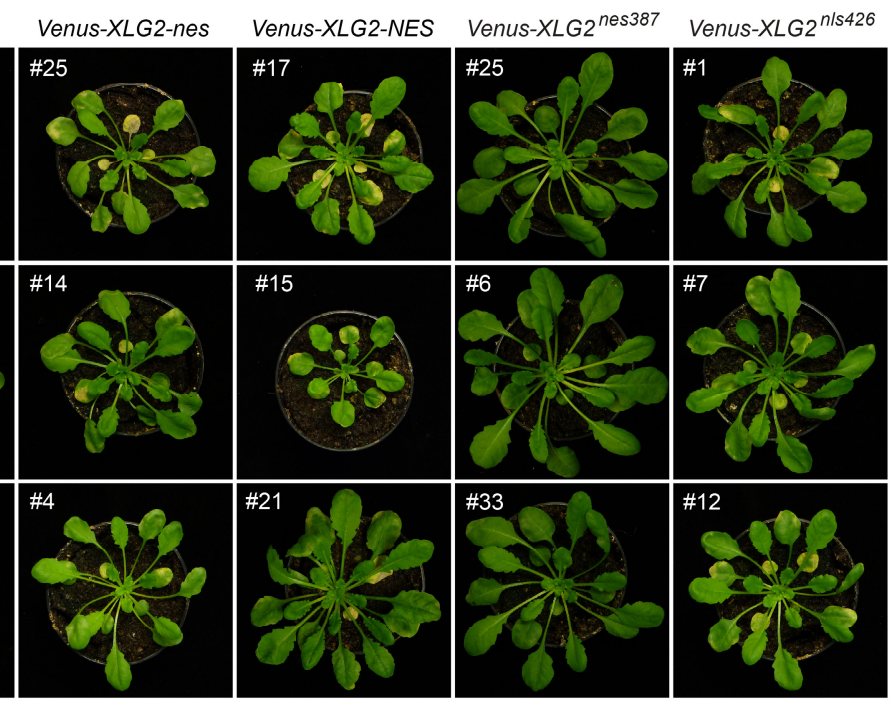

Figure 5: Cell periphery localisation of XLG2 is required for cerk1-4 cell death signalling

cerk1-4 xlg2-2 plants were transformed with pXLG2-Venus-XLG2-nIs/NLS/nes/NES and with $p X L G 2-V e n u s-X L G 2$ containing nes387 or nls426 mutations. (a) CLSM analysis of unchallenged leaves and leaves infected with $E$. cruciferarum (1 dpi). Images are maximum projections of z-stacks spanning the epidermal cell layer. Example nuclei are marked by arrowheads and the positions of fungal spores at sites of attempted penetration are outlined by dashed blue lines. Scale bar $=50 \mu \mathrm{m}$. (b) The indicated transgenic lines and controls were inoculated with $E$. cruciferarum and pictures were taken $14 \mathrm{dpi}$. Three independent lines per construct are shown. Transgenic protein levels in (c) Venus-XLG2-nls/NLS/nes/NES lines and (d) Venus-XLG2 $2^{\text {nes387 }} / \mathrm{XLG2}^{\text {nls426 }}$ lines were confirmed by Western blotting after $E$. cruciferarum infection. (e) The apparent mass of Venus-XLG2 $2^{\text {nes387 }}$ and Venus-XLG2 $2^{\text {ns } 426}$ was compared to Venus-XLG2 WT and Venus XLG2 ${ }^{\mathrm{E} 293 \mathrm{~K}}$ in a side-by-side Western Blot. CBB = Coomassie Brilliant Blue stained membrane. 
(a)

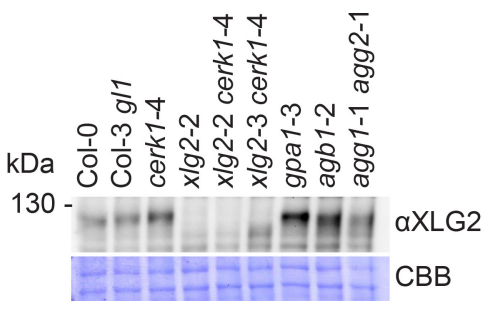

(b)

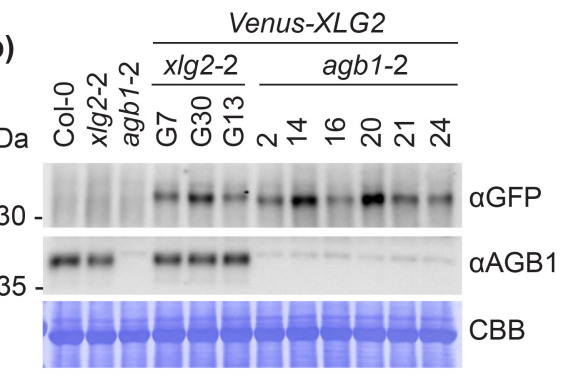

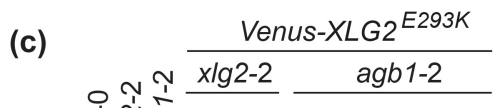

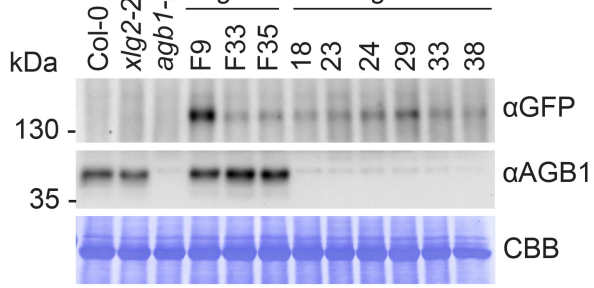

(d)

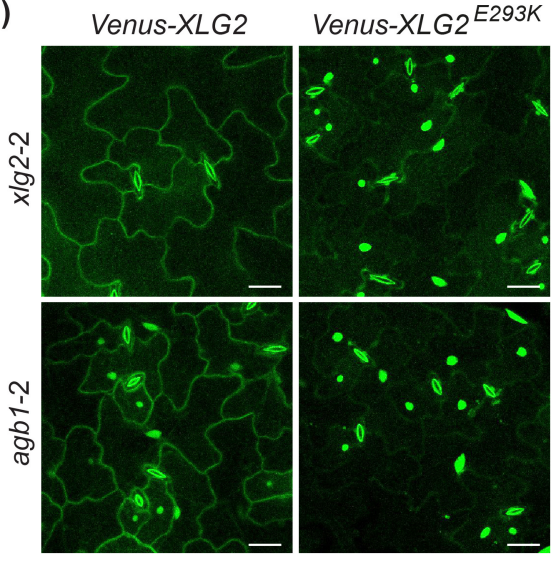

(e)

Venus-XLG2

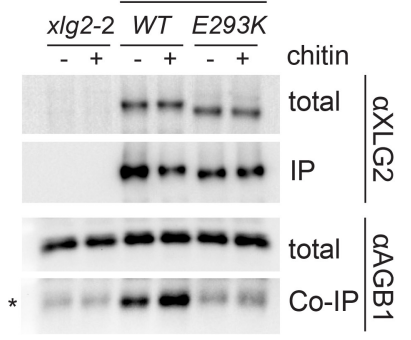

Figure 6: XLG2 localisation and protein modification are altered in agb1-2 and the non-functional XLG2 ${ }^{\mathrm{E2} 93 \mathrm{~K}}$ variant

(a) A Western blot of the indicated Arabidopsis lines with a specific XLG2 antibody reveals band shifts in $x / g 2-3$ (XLG2 ${ }^{\mathrm{E2} 93 \mathrm{~K}}$ ), agb1 and agg1 agg2. (b) Venus-XLG2 WT and (c) Venus XLG2 ${ }^{\mathrm{E2} 93 \mathrm{~K}}$ were stably expressed in $x / g 2-2$ and agb1-2. Western blots were performed with antibodies against Venus ( $\alpha$ GFP) and AGB1. CBB: Coomassie brilliant blue stained membranes. (d) CSLM images of Venus-XLG2 and Venus-XLG2 ${ }^{\mathrm{E} 293 \mathrm{~K}}$ stably expressed in $x / g 2-2$ and $a g b 1-$ 2. Images are maximum projections of 12 focal planes recorded $1 \mu \mathrm{m}$ apart. Size bar: $25 \mu \mathrm{m}$. (e) VenusXLG2/XLG2 ${ }^{\mathrm{E} 293 \mathrm{~K}}$ - AGB1 Co-IP assay. Total protein extracts (input) were prepared from untransformed $x / g 2-2$ as well as $x$ lg2-2 stably expressing Venus-XLG2 WT or Venus-XLG2 ${ }^{\mathrm{E2} 93 \mathrm{~K}}$. Pull-downs were performed with nanobody beads recognizing GFP/Venus. Input and pull down fractions were analysed using $\alpha \mathrm{GFP} /$ Venus and $\alpha \mathrm{AGB1}$ antibodies. *AGB1 shows low levels of unspecific binding to the beads in absence of XLG2. 
(a)

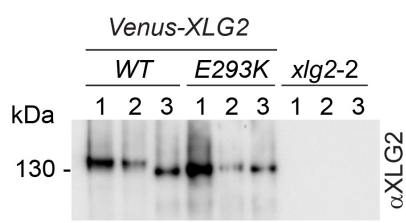

(c)

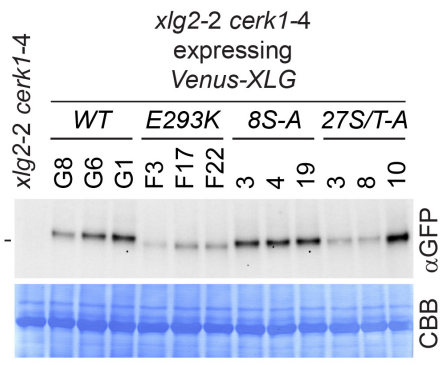

(e)
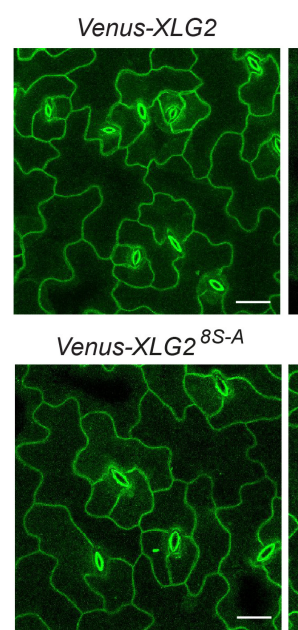

Venus-XLG2 ${ }^{8 S-A}$
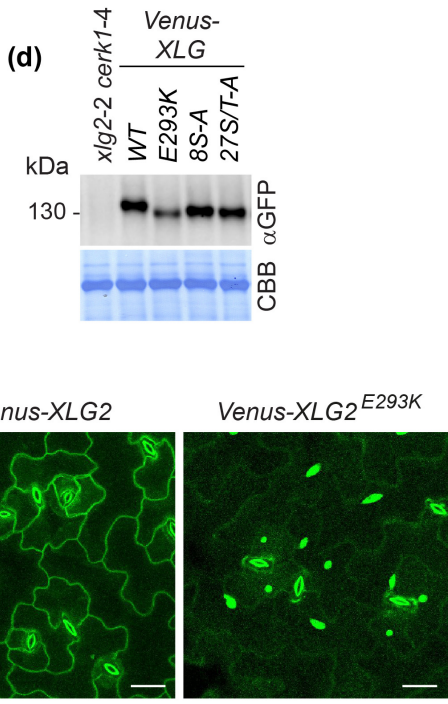

Venus-XLG2 $27 S / T-A$

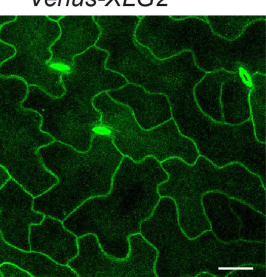

(b)

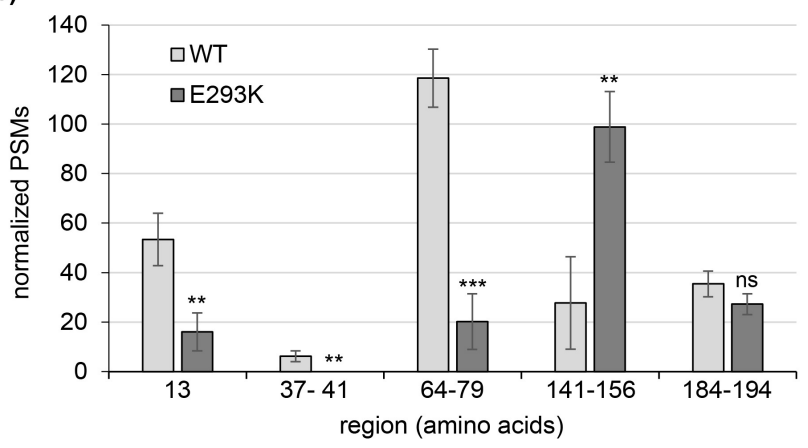

(f)
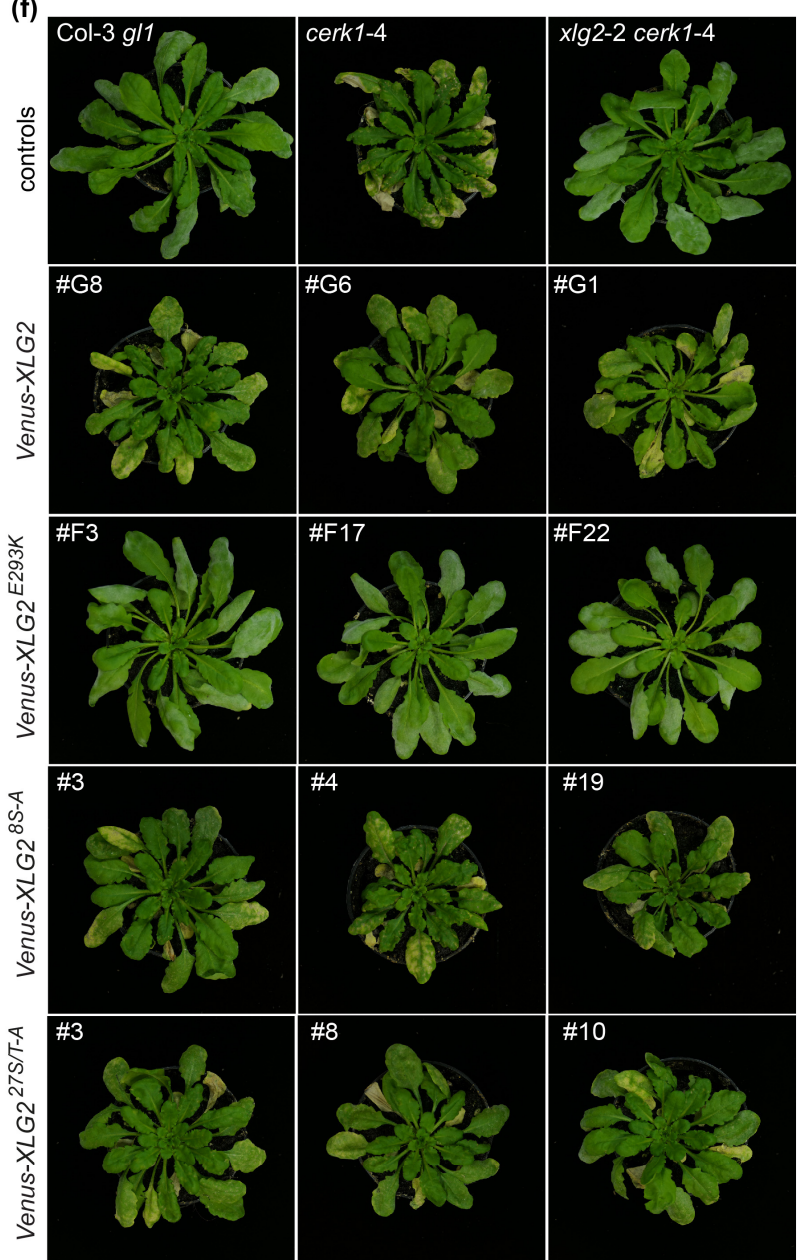

Figure 7: Phosphorylation of the XLG2 N-terminal region affects protein mobility in Western blots, but not XLG2 subcellular localisation and function in the cerk1-4 signalling pathway

(a) De-phosphorylation assay: Venus-XLG2 (WT) and Venus-XLG2 ${ }^{\mathrm{E} 293 \mathrm{~K}}$ were purified from Arabidopsis plants via the Venus tag and either frozen directly (1), incubated with assay buffer (2) or incubated with assay buffer containing Lambda phosphatase (3). Western blotting was performed with a XLG2-specific antibody and $x$ lg2-2 was included as a negative control. (b) Phosphoproteomic analysis of Venus-XLG2 (WT) and Venus-XLG2 ${ }^{\mathrm{E2} 93 \mathrm{~K}}$ expressed in the $x / g 2-2$ background. Peptide spectrum matches (PSMs) corresponding to phosphorylated peptides were acquired in tSIM mode and normalized to overall XLG2 PSM counts. Numbers of phospho-PSMs covering the indicated amino acid (aa) regions are shown. Data are averages of three independent transgenic lines $\pm S D$. (c-f) $x / g 2-2$ cerk1-4 plants were transformed with $p X L G 2-V e n u s-X L G 2$ (WT), Venus-XLG2 ${ }^{E 293 K}$, Venus- $X L G 2^{8 S-A}$ or Venus- $X L G 2^{275 / T-A}$. (c) Western blots of three transgenic lines each, using an anti-GFP/Venus antibody. The genetic background $x / g 2-2$ cerk1-4 is shown as a negative control. (d) Western blot for direct comparison of SDS-PAGE motility of the indicated fusion proteins. (e) CLSM images of epidermal cells of the indicated transgenic lines. Pictures are maximum projections of 12 focal planes recorded $1 \mu \mathrm{m}$ apart. Size bar $=25 \mu \mathrm{m}$. (f) Transgenic lines and controls were inoculated with E. cruciferarum and images were taken $14 \mathrm{dpi}$. Three independent lines are shown per construct. 
(a)

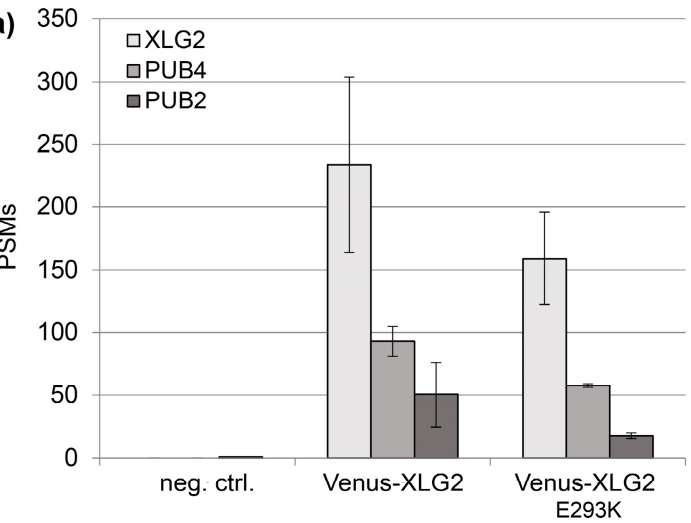

(b)

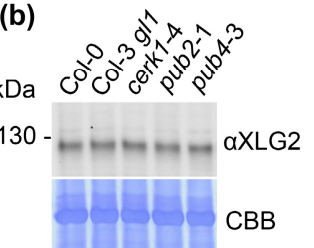

(c)
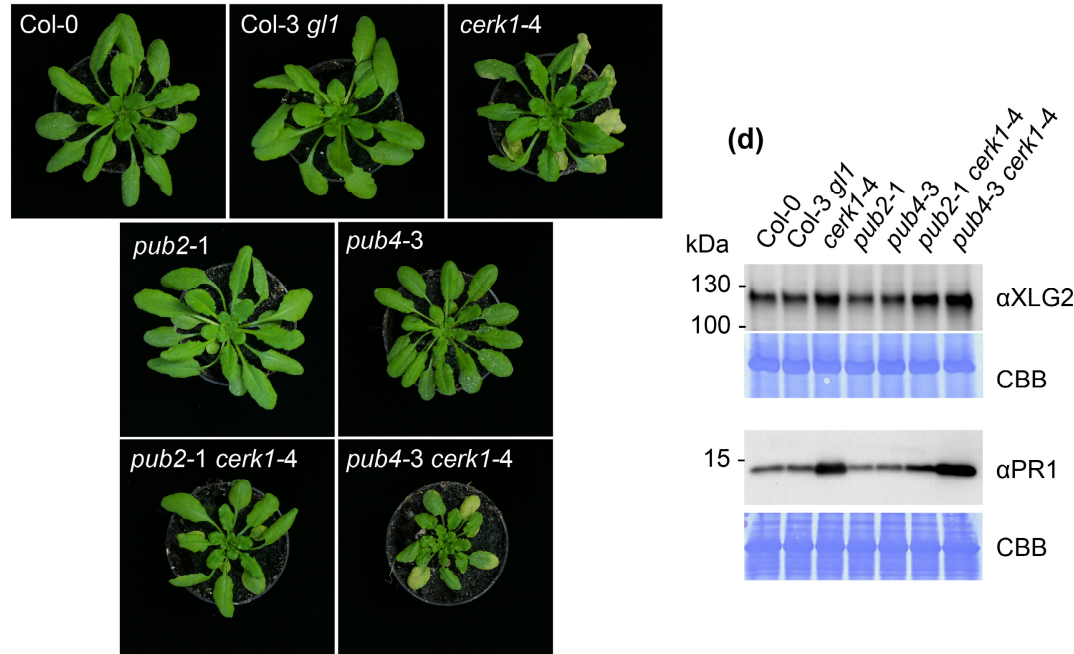

Figure 8: XLG2 functions in cerk1-4 cell death signalling together with PUB2.

(a) Venus-XLG2 and Venus-XLG2 ${ }^{\mathrm{E} 293 \mathrm{~K}}$ were isolated from stably transformed Arabidopsis lines with anti-GFP nanobody beads. The samples were analysed by LC-MS/MS and PSMs matching XLG2/XLG2 ${ }^{\mathrm{E} 293 \mathrm{~K}}$, PUB4 and PUB2 were counted. Data are presented as average \pm SD of three independent transgenic lines. Untransformed $x / g 2-2$ served as a negative control. (b) Western blot of the indicated lines with a specific XLG2 antibody. (c,d) pub2-1 and pub4-3 were crossed with cerk1-4. Single and double mutants as well as the background accessions Col-0 and Col-3 g/1 were inoculated with Bgh and analysed 7dpi. (c) Images of representative plants. (d) 6 whole rosettes per genotype were pooled and used for Western blots with XLG2 and PR1-specific antibodies. CBB = Coomassie brilliant blue stained membrane. 


\section{REFERENCES}

Aranda-Sicilia MN, Trusov Y, Maruta N, Chakravorty D, Zhang Y, Botella JR. 2015. Heterotrimeric $\mathrm{G}$ proteins interact with defense-related receptor-like kinases in Arabidopsis. Journal of plant physiology 188: 44-48.

Barghahn S, Arnal G, Jain N, Petutschnig E, Brumer H, Lipka V. 2021. Mixed Linkage beta1,3/1,4-Glucan Oligosaccharides Induce Defense Responses in Hordeum vulgare and Arabidopsis thaliana. Frontiers in plant science 12: 682439.

Brachmann CB, Davies A, Cost GJ, Caputo E, Li J, Hieter P, Boeke JD. 1998. Designer deletion strains derived from Saccharomyces cerevisiae S288C: a useful set of strains and plasmids for PCR-mediated gene disruption and other applications. Yeast 14(2): 115132.

Chakravorty D, Assmann SM. 2018. G protein subunit phosphorylation as a regulatory mechanism in heterotrimeric $\mathrm{G}$ protein signaling in mammals, yeast, and plants. The Biochemical journal 475(21): 3331-3357.

Chakravorty D, Gookin TE, Milner MJ, Yu Y, Assmann SM. 2015. Extra-Large G Proteins Expand the Repertoire of Subunits in Arabidopsis Heterotrimeric G Protein Signaling. Plant Physiology 169(1): 512-529.

Cheng CY, Krishnakumar V, Chan AP, Thibaud-Nissen F, Schobel S, Town CD. 2017. Araport11: a complete reannotation of the Arabidopsis thaliana reference genome. The Plant journal : for cell and molecular biology 89(4): 789-804.

Christianson TW, Sikorski RS, Dante M, Shero JH, Hieter P. 1992. Multifunctional yeast highcopy-number shuttle vectors. Gene 110(1): 119-122.

Derkacheva M, Gang Yu, Jose S. Rufian, Shushu Jiang, Paul Derbyshire, Rafael J. L. Morcillo, Lena Stransfeld, Yali Wei, L.H. F, Menke, et al. 2020. The Arabidopsis E3 ubiquitin ligase PUB4 regulates BIK1 homeostasis and is targeted by a bacterial type-III effector. BioRxiv.

Desaki Y, Takahashi S, Sato K, Maeda K, Matsui S, Yoshimi I, Miura T, Jumonji JI, Takeda J, Yashima K, et al. 2019. PUB4, a CERK1-Interacting Ubiquitin Ligase, Positively Regulates MAMP-Triggered Immunity in Arabidopsis. Plant \& cell physiology 60(11): 2573-2583.

Ding L, Pandey S, Assmann SM. 2008. Arabidopsis extra-large G proteins (XLGs) regulate root morphogenesis. The Plant journal : for cell and molecular biology 53(2): 248-263.

Escocard de Azevedo Manhaes AM, Ortiz-Morea FA, He P, Shan L. 2021. Plant plasma membrane-resident receptors: Surveillance for infections and coordination for growth and development. Journal of Integrative Plant Biology 63(1): 79-101.

Gao M, Wang X, Wang D, Xu F, Ding X, Zhang Z, Bi D, Cheng YT, Chen S, Li X, et al. 2009. Regulation of cell death and innate immunity by two receptor-like kinases in Arabidopsis. Cell Host \& Microbe 6(1): 34-44.

Garcia AV, Blanvillain-Baufume S, Huibers RP, Wiermer M, Li G, Gobbato E, Rietz S, Parker JE. 2010. Balanced nuclear and cytoplasmic activities of EDS1 are required for a complete plant innate immune response. PLoS pathogens 6: e1000970.

Ghareeb H, Laukamm S, Lipka V. 2016. COLORFUL-Circuit: A Platform for Rapid Multigene Assembly, Delivery, and Expression in Plants. Frontiers in plant science 7: 246.

Hartwig B, James GV, Konrad K, Schneeberger K, Turck F. 2012. Fast isogenic mapping-bysequencing of ethyl methanesulfonate-induced mutant bulks. Plant Physiology 160(2): 591-600.

Hellens RP, Edwards EA, Leyland NR, Bean S, Mullineaux PM. 2000. pGreen: a versatile and flexible binary Ti vector for Agrobacterium-mediated plant transformation. Plant Molecular Biology 42(6): 819-832. 
Heo JB, Sung S, Assmann SM. 2012. Ca2+-dependent GTPase, extra-large G protein 2 (XLG2), promotes activation of DNA-binding protein related to vernalization 1 (RTV1), leading to activation of floral integrator genes and early flowering in Arabidopsis. The Journal of Biological Chemistry 287(11): 8242-8253.

Hubner NC, Bird AW, Cox J, Splettstoesser B, Bandilla P, Poser I, Hyman A, Mann M. 2010. Quantitative proteomics combined with BAC TransgeneOmics reveals in vivo protein interactions. The Journal of cell biology 189(4): 739-754.

Jones AM, Ecker JR, Chen JG. 2003. A reevaluation of the role of the heterotrimeric $G$ protein in coupling light responses in Arabidopsis. Plant physiology 131(4): 1623-1627.

Jones JC, Duffy JW, Machius M, Temple BR, DohIman HG, Jones AM. 2011. The crystal structure of a self-activating $G$ protein alpha subunit reveals its distinct mechanism of signal initiation. Science signaling 4(159): ra8.

Kemmerling B, Schwedt A, Rodriguez P, Mazzotta S, Frank M, Qamar SA, Mengiste T, Betsuyaku S, Parker JE, Müssig C, et al. 2007. The BRI1-associated kinase 1, BAK1, has a brassinolide-independent role in plant cell-death control. Current Biology: $C B$ 17(13): 1116-1122.

Lee YR, Assmann SM. 1999. Arabidopsis thaliana 'extra-large GTP-binding protein' (AtXLG1): a new class of G-protein. Plant Molecular Biology 40(1): 55-64.

Leslie ME, Lewis MW, Youn JY, Daniels MJ, Liljegren SJ. 2010. The EVERSHED receptor-like kinase modulates floral organ shedding in Arabidopsis. Development 137(3): 467-476.

Liang X, Ding P, Lian K, Wang J, Ma M, Li L, Li M, Zhang X, Chen S, Zhang Y, et al. 2016. Arabidopsis heterotrimeric $\mathrm{G}$ proteins regulate immunity by directly coupling to the FLS2 receptor. elife 5: e13568.

Liang X, Ma M, Zhou Z, Wang J, Yang X, Rao S, Bi G, Li L, Zhang X, Chai J, et al. 2018. Ligandtriggered de-repression of Arabidopsis heterotrimeric $G$ proteins coupled to immune receptor kinases. Cell Research 28(5): 529-543.

Liu J, Ding P, Sun T, Nitta Y, Dong O, Huang X, Yang W, Li X, Botella JR, Zhang Y. 2013. Heterotrimeric $\mathrm{G}$ proteins serve as a converging point in plant defense signaling activated by multiple receptor-like kinases. Plant Physiology 161(4): 2146-2158.

Liu Y, Huang X, Li M, He P, Zhang Y. 2016. Loss-of-function of Arabidopsis receptor-like kinase BIR1 activates cell death and defense responses mediated by BAK1 and SOBIR1. The New Phytologist 212(3): 637-645.

Lou F, Abramyan TM, Jia H, Tropsha A, Jones AM. 2020. An atypical heterotrimeric Galpha protein has substantially reduced nucleotide binding but retains nucleotideindependent interactions with its cognate RGS protein and Gbetagamma dimer. Journal of biomolecular structure \& dynamics 38(17): 5204-5218.

Maruta N, Trusov Y, Brenyah E, Parekh U, Botella JR. 2015. Membrane-Localised Extra-Large G-Proteins and Gbetagamma of the Heterotrimeric G Proteins Form Functional Complexes Engaged in Plant Immunity in Arabidopsis. Plant Physiology.

Maruta N, Trusov Y, Chakravorty D, Urano D, Assmann SM, Botella JR. 2019. Nucleotide exchange-dependent and nucleotide exchange-independent functions of plant heterotrimeric GTP-binding proteins. Science signaling 12(606).

Maruta N, Trusov Y, Urano D, Chakravorty D, Assmann SM, Jones AM, Botella JR. 2021. GTP binding by Arabidopsis extra-large $\mathrm{G}$ protein 2 is not essential for its functions. Plant Physiology.

Ofoe R. 2021. Signal transduction by plant heterotrimeric G-protein. Plant biology 23(1): 3-10. Okamoto H, Matsui M, Deng XW. 2001. Overexpression of the heterotrimeric G-protein alphasubunit enhances phytochrome-mediated inhibition of hypocotyl elongation in 
Arabidopsis. The Plant Cell 13(7): 1639-1652.

Oldham WM, Hamm HE. 2008. Heterotrimeric G protein activation by G-protein-coupled receptors. Nature reviews. Molecular cell biology 9(1): 60-71.

Pandey S. 2019. Heterotrimeric G-Protein Signaling in Plants: Conserved and Novel Mechanisms. Annual Review of Plant Biology 70: 213-238.

Pandey S. 2020. Plant receptor-like kinase signaling through heterotrimeric G-proteins. Journal of Experimental Botany.

Petutschnig EK, Jones AM, Serazetdinova L, Lipka U, Lipka V. 2010. The lysin motif receptorlike kinase (LysM-RLK) CERK1 is a major chitin-binding protein in Arabidopsis thaliana and subject to chitin-induced phosphorylation. J Biol Chem 285(37): 28902-28911.

Petutschnig EK, Stolze M, Lipka U, Kopischke M, Horlacher J, Valerius O, Rozhon W, Gust AA, Kemmerling B, Poppenberger B, et al. 2014. A novel Arabidopsis CHITIN ELICITOR RECEPTOR KINASE 1 (CERK1) mutant with enhanced pathogen-induced cell death and altered receptor processing. The New Phytologist.

Rappsilber J, Mann M, Ishihama Y. 2007. Protocol for micro-purification, enrichment, prefractionation and storage of peptides for proteomics using StageTips. Nature protocols 2(8): 1896-1906.

Roux M, Schwessinger B, Albrecht C, Chinchilla D, Jones A, Holton N, Malinovsky FG, Tör M, de Vries S, Zipfel C. 2011. The Arabidopsis leucine-rich repeat receptor-like kinases BAK1/SERK3 and BKK1/SERK4 are required for innate immunity to hemibiotrophic and biotrophic pathogens. The Plant Cell 23(6): 2440-2455.

Roy Choudhury S, Pandey S. 2016. Interaction of Heterotrimeric G-Protein Components with Receptor-like Kinases in Plants: An Alternative to the Established Signaling Paradigm? Molecular plant 9(8): 1093-1095.

Schwessinger B, Roux M, Kadota Y, Ntoukakis V, Sklenar J, Jones A, Zipfel C. 2011. Phosphorylation-dependent differential regulation of plant growth, cell death, and innate immunity by the regulatory receptor-like kinase BAK1. PLoS Genetics 7(4): e1002046-e1002046.

Torres MA, Dangl JL, Jones JD. 2002. Arabidopsis gp91phox homologues AtrbohD and AtrbohF are required for accumulation of reactive oxygen intermediates in the plant defense response. Proceedings of the National Academy of Sciences of the United States of America 99(1): 517-522.

Trusov Y, Rookes JE, Tilbrook K, Chakravorty D, Mason MG, Anderson D, Chen JG, Jones AM, Botella JR. 2007. Heterotrimeric $G$ protein gamma subunits provide functional selectivity in Gbetagamma dimer signaling in Arabidopsis. The Plant Cell 19(4): 12351250.

Tunc-Ozdemir M, Urano D, Jaiswal DK, Clouse SD, Jones AM. 2016. Direct Modulation of Heterotrimeric G Protein-coupled Signaling by a Receptor Kinase Complex. The Journal of Biological Chemistry 291(27): 13918-13925.

Ullah H, Chen JG, Temple B, Boyes DC, Alonso JM, Davis KR, Ecker JR, Jones AM. 2003. The beta-subunit of the Arabidopsis $\mathrm{G}$ protein negatively regulates auxin-induced cell division and affects multiple developmental processes. The Plant Cell 15(2): 393-409.

Urano D, Jones AM. 2014. Heterotrimeric G protein-coupled signaling in plants. Annual Review of Plant Biology 65: 365-384.

Wang H, Lu Y, Jiang T, Berg H, Li C, Xia Y. 2013. The Arabidopsis U-box/ARM repeat E3 ligase AtPUB4 influences growth and degeneration of tapetal cells, and its mutation leads to conditional male sterility. The Plant journal : for cell and molecular biology 74(3): 511523. 
Wang J, Grubb LE, Liang X, Li L, Gao C, Ma M, Feng F, Li M, Zhang X, Yu F, et al. 2018. A Regulatory Module Controlling Homeostasis of a Plant Immune Kinase. Molecular Cell 69(3): 493-504 e496.

Wang Y, Wu Y, Yu B, Yin Z, Xia Y. 2017. EXTRA-LARGE G PROTEINs Interact with E3 Ligases PUB4 and PUB2 and Function in Cytokinin and Developmental Processes. Plant Physiology 173(2): 1235-1246.

Wu Y, Gao Y, Zhan Y, Kui H, Liu H, Yan L, Kemmerling B, Zhou JM, He K, Li J. 2020. Loss of the common immune coreceptor BAK1 leads to NLR-dependent cell death. Proceedings of the National Academy of Sciences of the United States of America 117(43): 2704427053.

Yu Y, Chakravorty D, Assmann SM. 2018. The G Protein beta-Subunit, AGB1, Interacts with FERONIA in RALF1-Regulated Stomatal Movement. Plant Physiology 176(3): 2426-2440.

Zhang H, Xie P, Xu X, Xie Q, Yu F. 2021. Heterotrimeric $G$ protein signalling in plant biotic and abiotic stress response. Plant biology 23 Suppl 1: 20-30.

Zhong CL, Zhang C, Liu JZ. 2019. Heterotrimeric G protein signaling in plant immunity. Journal of Experimental Botany 70(4): 1109-1118.

Zhu H, Li GJ, Ding L, Cui X, Berg H, Assmann SM, Xia Y. 2009. Arabidopsis extra large G-protein 2 (XLG2) interacts with the Gbeta subunit of heterotrimeric $G$ protein and functions in disease resistance. Molecular plant 2(3): 513-525. 


\section{Supporting Information}

834

835

836

837

838

839

840

841

842

843

844

845

846

847

848

849

850

851

852

853

854

855

856

857

858

859

860

861

862

863

864

865

866

867

868

869

870

871

872

\section{SUPPLEMENTAL MATERIALS AND METHODS}

\section{Mass Spectrometry}

After GFP pull-down, on bead trypsin digestion was performed as described in a protocol provided by the manufacturer Chromotek, which is based on (Hubner et al., 2010). Digested peptides were purified with the C18 stop and go extraction (Stage) method (Rappsilber et al., 2007). Purified peptides were vacuum dried at $45^{\circ} \mathrm{C}$ and then dissolved in $20 \mu \mathrm{l} 2 \%$ acetonitrile, $0.1 \%$ formic acid.

3-4 $\mu \mathrm{l}$ of each sample were subjected to reversed-phase liquid chromatography for peptide separation using an RSLCnano Ultimate 3000 system (Thermo Fisher Scientific). Peptides were loaded on an Acclaim ${ }^{\oplus}$ PepMap 100 pre-column (100 $\mu \mathrm{m} \times 2 \mathrm{~cm}, \mathrm{C} 18,5 \mu \mathrm{m}, 100 \AA$ A Thermo Fisher Scientific) with $0.07 \%$ trifluoroacetic acid. Analytical separation of peptides was done on an Acclaim ${ }^{\oplus}$ PepMap RSLC column (75 $\mu \mathrm{m} \times 50 \mathrm{~cm}, \mathrm{C} 18,2 \mu \mathrm{m}, 100 \AA$ A ; Thermo Fisher Scientific) running a water-acetonitrile gradient at a flow rate of $300 \mathrm{nl} / \mathrm{min}$. All solvents and acids had Optima grade for LC-MS (Thermo Fisher Scientific). Chromatographically eluting peptides were on-line ionized by nano-electrospray ( $\mathrm{nESI}$ ) using the Nanospray Flex Ion Source (Thermo Fisher Scientific) at $1.5 \mathrm{kV}$ (liquid junction) and continuously transferred into the mass spectrometer ( $Q$ Exactive HF, Thermo Fisher Scientific). Full scans in a mass range of 300 to $1650 \mathrm{~m} / \mathrm{z}$ were recorded at a resolution of 30,000 followed by data-dependent top 10 fragmentation (HCD) at a resolution of 15,000 (dynamic exclusion enabled).

For targeted single-ion monitoring (tSIM) LC-MS runs, the resolution was set to 60,000. The maximum ion time for tSIM scans (AGC target 1e6) was $100 \mathrm{~ms}$. The loop count equalled the number of $\mathrm{m} / \mathrm{z}$ values on the inclusion list. Dynamic exclusion was disabled. LC-MS method programming and data acquisition was performed with the XCalibur software 4.0 (Thermo Fisher Scientific).

Database searches were performed using Proteome Discoverer 2.2 software (Thermo Fisher Scientific) with the Mascot and SequestHT search algorithms against the Araport11 protein database (Cheng et al., 2017). The digestion mode was set to trypsin and the maximum number of missed cleavage sites was set to three. Carbamidomethylation of cysteines was set as fixed modification, oxidation of methionine and serine, threonine and tyrosine phosphorylation were set as variable modifications. The mass tolerance was $10 \mathrm{ppm}$ for precursor ions and $0.02 \mathrm{Da}$ for fragment ions. The decoy mode was rev with a false discovery rate of 0.01 .

Phosphopeptides were identified in initial runs and then selected for quantitative analysis by tSIM. Phosphorylation sites within phosphopeptides were assigned with the ptmRS node of Proteome Discoverer 2.2 (Thermo Fisher Scientific). Many partially overlapping phosphopeptides were found and unambiguous identification of phosphorylation sites could be achieved for approximately $50 \%$ of obtained spectra. Therefore, phosphopeptides were grouped into distinct, non-overlapping clusters. Phosphorylation within these was quantified by counting 
873 phosphorylated peptide spectrum matches (PSMs) and normalizing them to all PSMs obtained

874 for XLG2.

\section{Cloning}

876 For generation of complementation constructs, a genomic fragment containing the $X L G 2$ coding 877 region and $1260 \mathrm{bp}$ of upstream sequence was amplified with primers EP209 and EP210 (Table 878 S1). The PCR product was cloned into a pGreenll-0229 (Hellens et al., 2000) derivative that 879 contains a modified MCS and the 35 S terminator, via its Ascl and BamHI sites.

880 pGreenll-0229-pXLG2-Venus-XLG2 and XLG2 ${ }^{E 293 K}$ were cloned by homologous recombination in 881 yeast. PCR products of $p X L G 2$, Venus and the $X L G 2 / X L G 2^{E 293 K}$ coding region were amplified with 882 primer pairs CM82 and CM92, JE23 and CM93, CM94 and CM83 respectively (Table S1). The 883 primers introduced overlaps between the PCR products and with the shuttle vector pRS426 884 (Christianson et al., 1992) as well as Ascl and BamHI sites for downstream cloning. Saccharomyces 885 cerevisiae strain S288c BY4741 (Brachmann et al., 1998) was transformed with a mix of PCR 886 fragments to be recombined and pRS426 linearized with $\mathrm{BamHI}$ and $\mathrm{Kpnl}$. Cells were then plated 887 on SC plates (-Ura +Gluc) and incubated at $28^{\circ} \mathrm{C}$ for $2-3$ days. Transformed S. cerevisiae cells 888 were washed from plates with water, pelleted by centrifugation ( $5 \mathrm{~min}, 4000 \mathrm{~g}, \mathrm{RT})$, resuspended 889 in $200 \mu \mathrm{l} \mathrm{P1}$ buffer of the QIAGEN Plasmid Midi kit and disrupted by incubation on a vibrax with $890 \quad 0.3 \mathrm{~g}$ glass beads (425-600 micron) for 10 - 15 minutes. Subsequently, glass beads were pelleted 891 by centrifugation and plasmids were prepared according to the kit manual. The pRS426 vector 892 construct was transformed into E. coli TOP10 cells for amplification. Next, the plasmid was 893 isolated and cut with $\mathrm{AsCl}$ and $\mathrm{BamHI}$ for cloning into a modified pGreenll-0229 vector. The 894 mutations nls426, nes387, C214/217A, C229/232/237/240A and C254/257A were introduced to 895 pGreenll-0229-pXLG2-Venus-XLG2 using the NEB Q5m Site Directed Mutagenesis kit and primers 896 listed in Table S1. In order to add c-terminal NLS/NES/nls/nes sequences, an additional Notl site 897 was introduced after the XLG2 coding region by site directed mutagenesis with primers JF17 and 898 JF18. The resulting vector was linearized with Notl and BamHI and ligated with annealed 899 oligonucleotide pairs JF19 and JF20, JF21 and JF22, JF30 and JF31 or JF32 and JF33 (Table S1). For 900 the 8S-A and 27S/T-A mutations, synthetic DNA fragments containing the mutations were 901 purchased (Thermo Fisher Scientific) and amplified with primers EP624 and EP629 (Table S1). A 902 PCR on pGreenll-0229-pXLG2-Venus-XLG2 was carried out with primers EP625 and EP220 (Table $903 \mathrm{~S} 1$ ) and the two fragments were joined with Gibson assembly.

904 All constructs were confirmed by sequencing, transformed into Agrobacterium tumefaciens 905 GV3101 (pSoup) and used for stable transformation of Arabidopsis plants. 


\section{SUPPLEMENTAL FIGURES and FIGURE LEGEND}

(a)
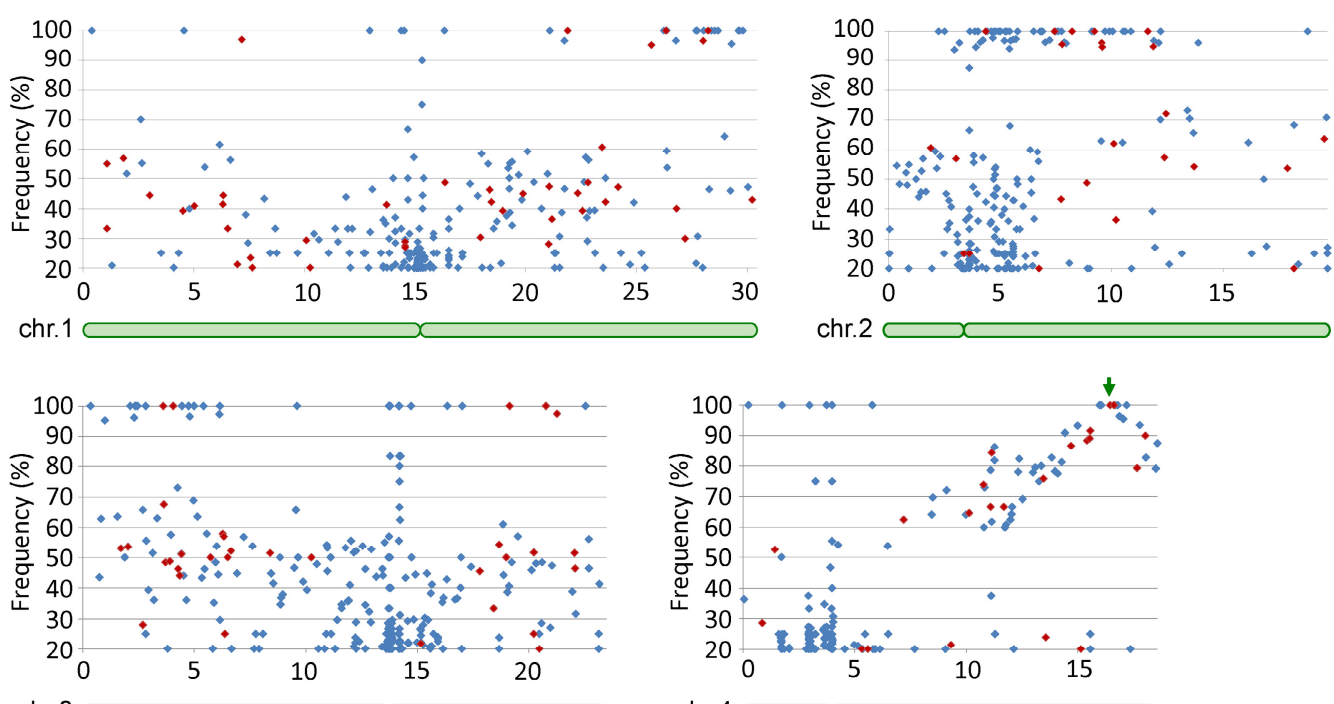

chr. 2

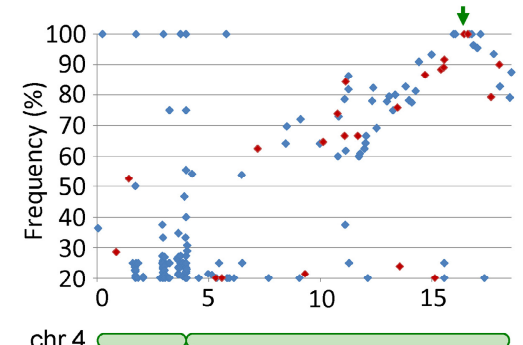

chr. 3

chr.4

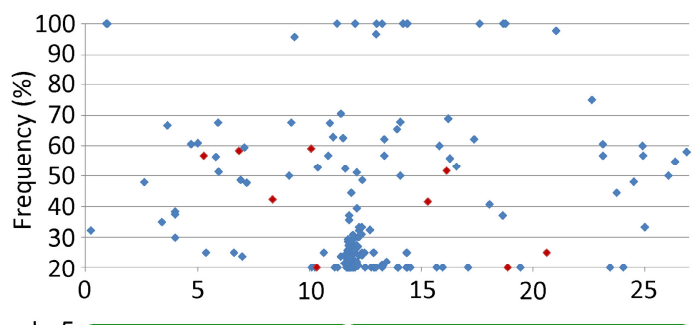

chr. 5

(b)

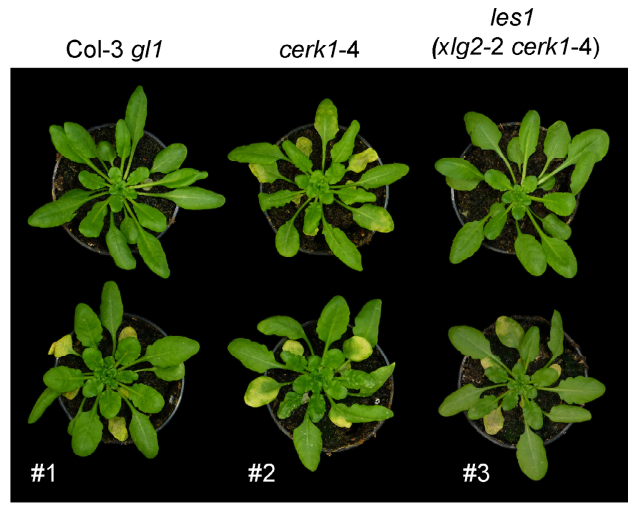

les1 (xlg2-2 cerk1-4) expressing $p X L G 2-X L G 2$ (c)

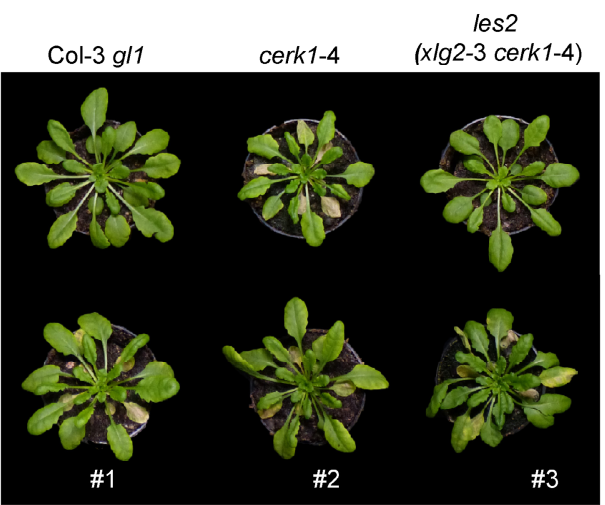

les2 (xlg2-3 cerk1-4) expressing $p X L G 2-X L G 2$

Figure S1: Mapping and complementation of les mutations

(a) les1 was backcrossed to cerk1-4 and in the F2 generation, powdery mildew-induced macroscopic cell death was scored. DNA of 31 suppressor plants was pooled and Illumina sequenced. Reads were aligned to the TAIR10 genome and SNPs identified. The frequencies of les1-specific SNPs were plotted against their position on the respective chromosomes ( $\mathrm{x}$-axis unit $=10^{6} \mathrm{bp}$ ). Synonymous mutations are shown as blue and non-synonymous mutations as red diamonds. The causative les 1 mutation in At4g34390 is marked with a green arrow and the chromosome arms are represented by green bars. (b, c) les1 (xlg2-2 cerk1-4) and les2 (xlg2-3 cerk1-4) plants were transformed with a genomic DNA fragment containing the wild type $X L G 2$ gene including its promoter. The resulting transgenic plants were inoculated with $B g h$ and images were taken after 7 or 10 days. The pictures show three independent transgenic lines as well as Col-3 gl1, cerk1-4 and les1 or les2 control plants. (b) and (c) are composite figures of 6 individual images. 
(a)

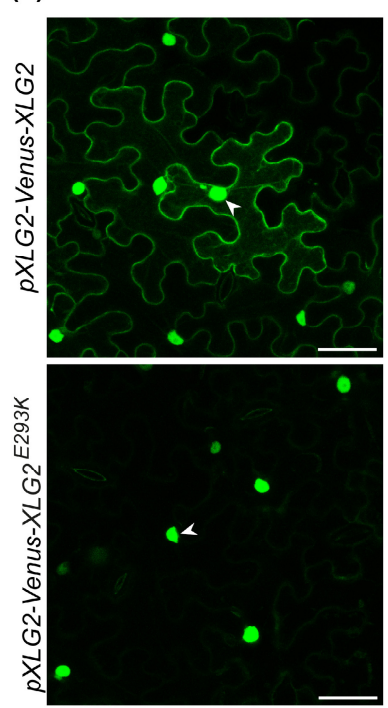

(b)

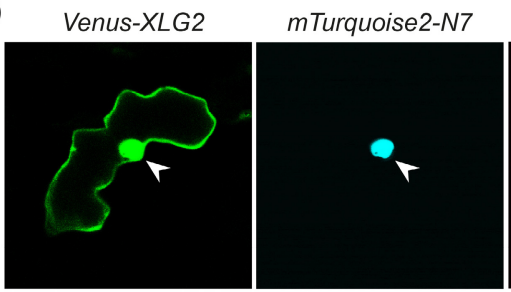

Venus-XLG2 ${ }^{\text {E293K }}$

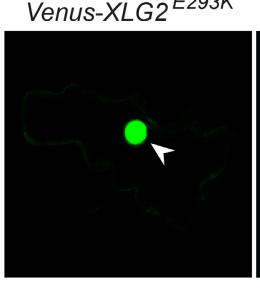

mTurquoise2-N7

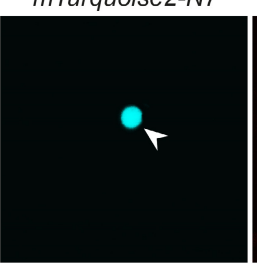

mKate2-Lti6b

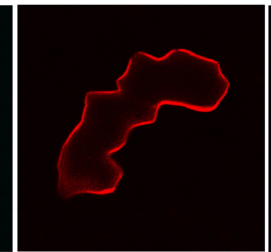

mKate2-Lti6b
Overlay

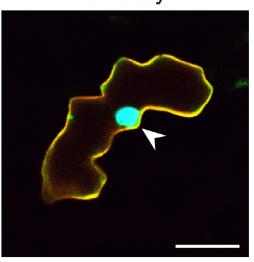

Overlay

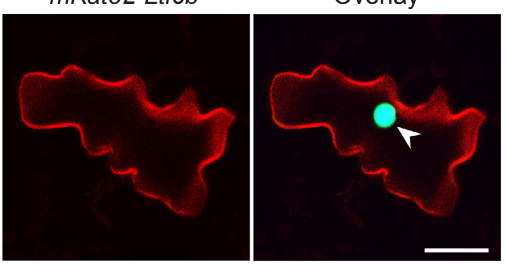

(c)
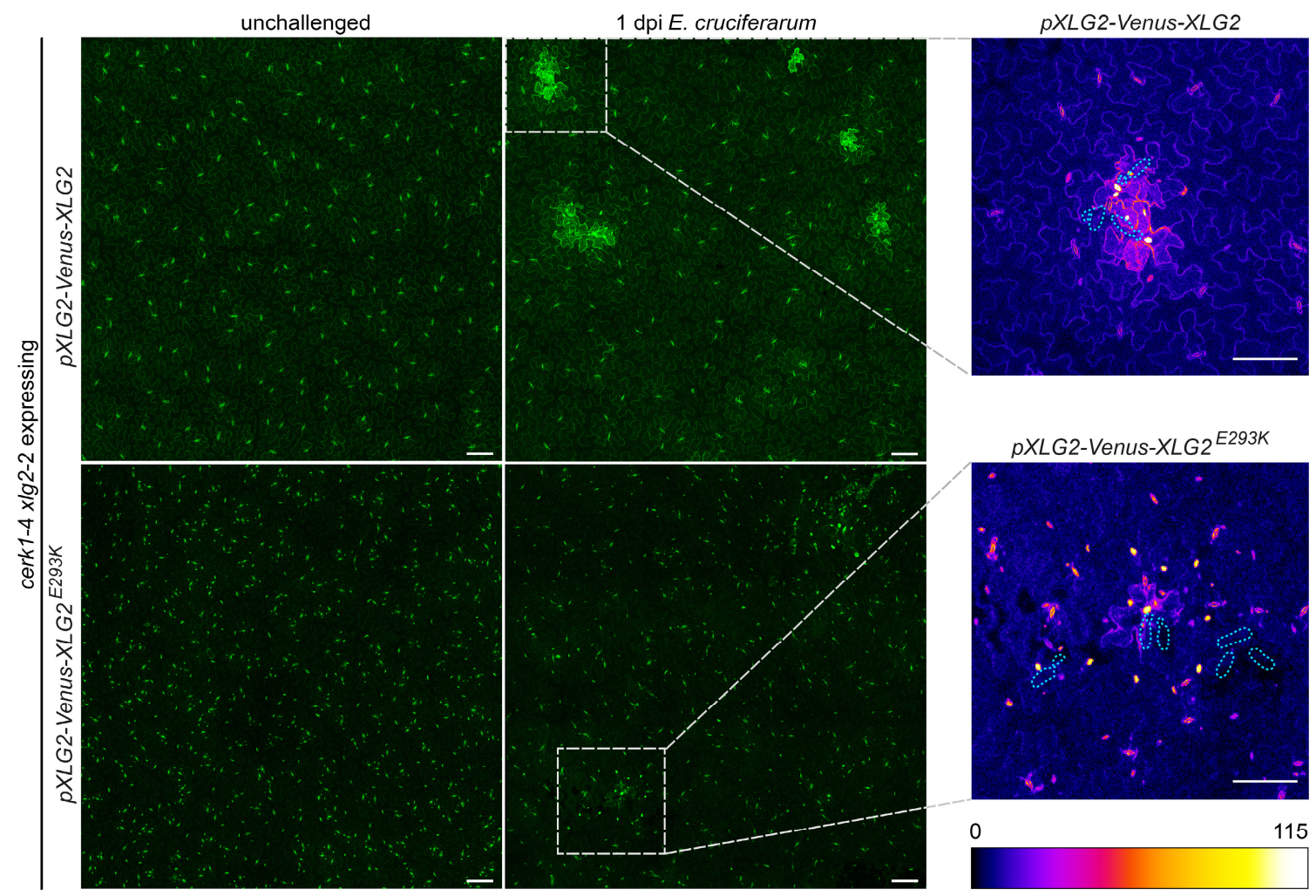

pXLG2-Venus-XLG2 ${ }^{\text {E293K }}$

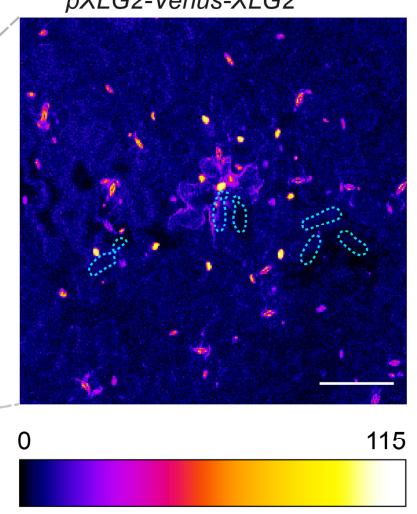

Figure S2: Localisation of Venus-XLG2 and Venus-XLG2 ${ }^{\mathrm{E} 293 \mathrm{~K}}$ in transient expression systems and stably transformed Arabidopsis plants

(a) Venus-XLG2 WT and Venus- XLG2 ${ }^{\mathrm{E} 293 \mathrm{~K}}$ were transiently expressed in $N$. benthamiana and CLSM was performed $3 \mathrm{dpi}$. Representative images are shown as maximum projections of 31 focal planes recorded $1 \mu \mathrm{m}$ apart. Scale bar $=$ $50 \mu \mathrm{m}$. (b) Particle bombardment in Arabidopsis xlg2-2 plants. Venus-XLG2 and Venus-XLG2 ${ }^{\mathrm{E} 293 \mathrm{~K}}$ were cotransformed with Turquoise2-N7 (nuclear marker) and mKate2-LTI6b (PM marker). Epidermal cells were analysed $2 \mathrm{~d}$ after bombardment and representative single plane images are shown. Scale bar $=50 \mu \mathrm{m}$. Nuclei are highlighted with arrowheads. (c) Leaf areas of transgenic Arabidopsis plants expressing Venus-XLG2 or Venus-XLG2 ${ }^{\mathrm{E} 293 \mathrm{~K}}$ in the cerk1-4 xlg2-2 background, unchallenged and 1dpi with E. cruciferarum. Images are stitched maximum projections of 60 focal planes recorded $1.5 \mu \mathrm{m}$ apart. Scale bar $=100 \mu \mathrm{m}$. On the right, zoom-ins of areas marked with dashed boxes are shown. Fungal spores are outlined with dashed blue lines. For better visualization of fluorescence levels, a multicolor lookup table was applied. Scale bar $=100 \mu \mathrm{m}$. 


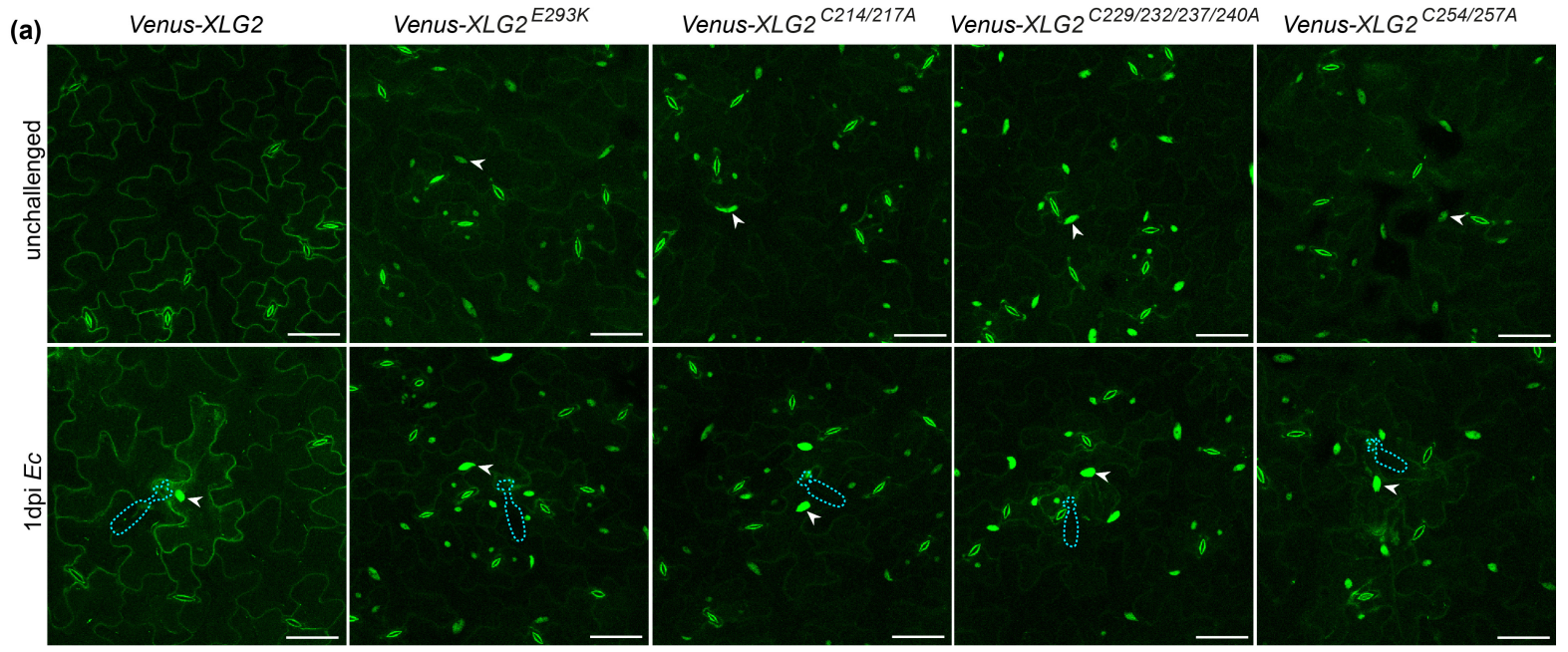

(b)
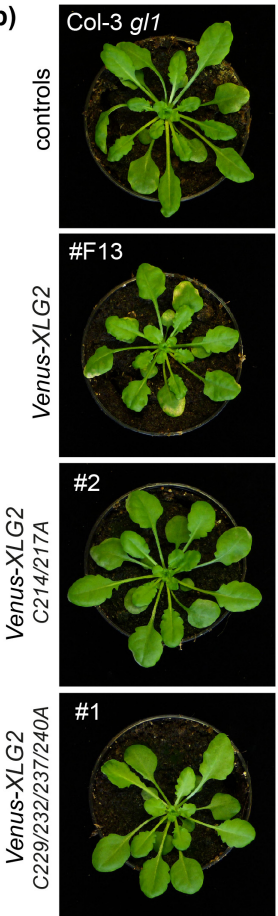

$\# 4$

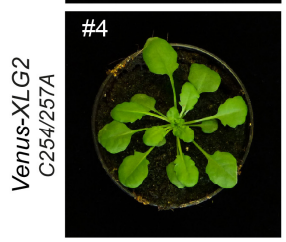

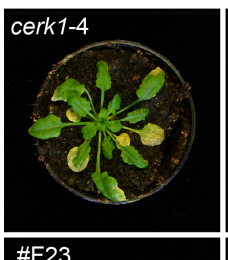
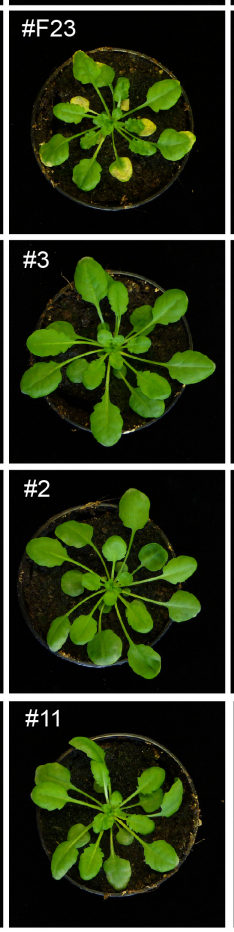

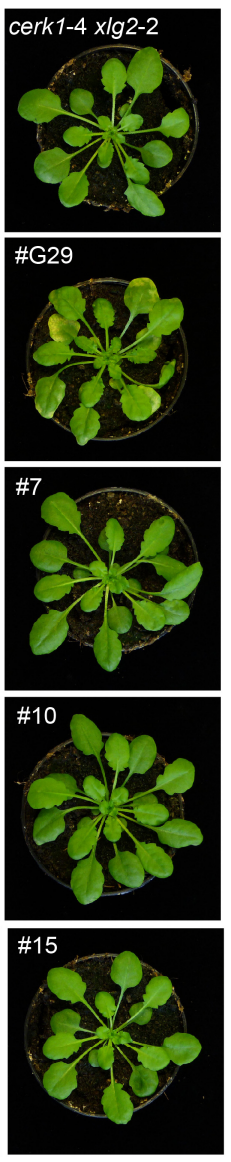

(c)

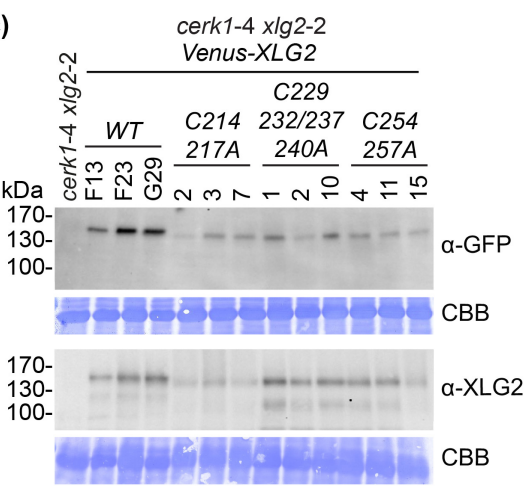

(d)

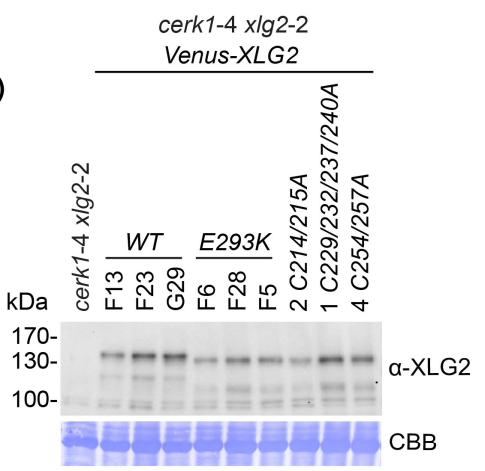

Figure S3: Signalling of XLG2 in the cerk1-4 pathway requires an intact cysteine-rich region

Stably transformed cerk1-4 xlg2-2 lines expressing Venus-XLG2, Venus-XLG2 ${ }^{\text {E293K }}$ or Venus-XLG2 with the indicated C to A mutations, were analysed. (a) Representative CLSM images of unchallenged and $E$. cruciferarum-infected plants (1 dpi). Pictures are maximum projections of z-stacks spanning the epidermal cell layer. Example nuclei are marked by arrowheads and the positions of fungal spores at sites of attempted penetration are outlined by dashed blue lines. Scale bar $=50 \mu \mathrm{m}$. (b) cerk1-4 x/g2-2 lines expressing the same constructs and non-transformed controls were inoculated with E. cruciferarum and images were taken $14 \mathrm{dpi}$. Three representative lines are shown. (c) Accumulation of Venus-XLG2 was confirmed by Western blotting after E. cruciferarum infection. (d) Apparent molecular masses of Venus$X L G 2$ wild type, $X L G 2^{\mathrm{E} 293 \mathrm{~K}}$ and the $\mathrm{C}$ to $\mathrm{A}$ mutant versions were compared in Western blots by running them side by side. $\mathrm{CBB}=$ Coomassie brilliant blue stained membrane. 
(a)

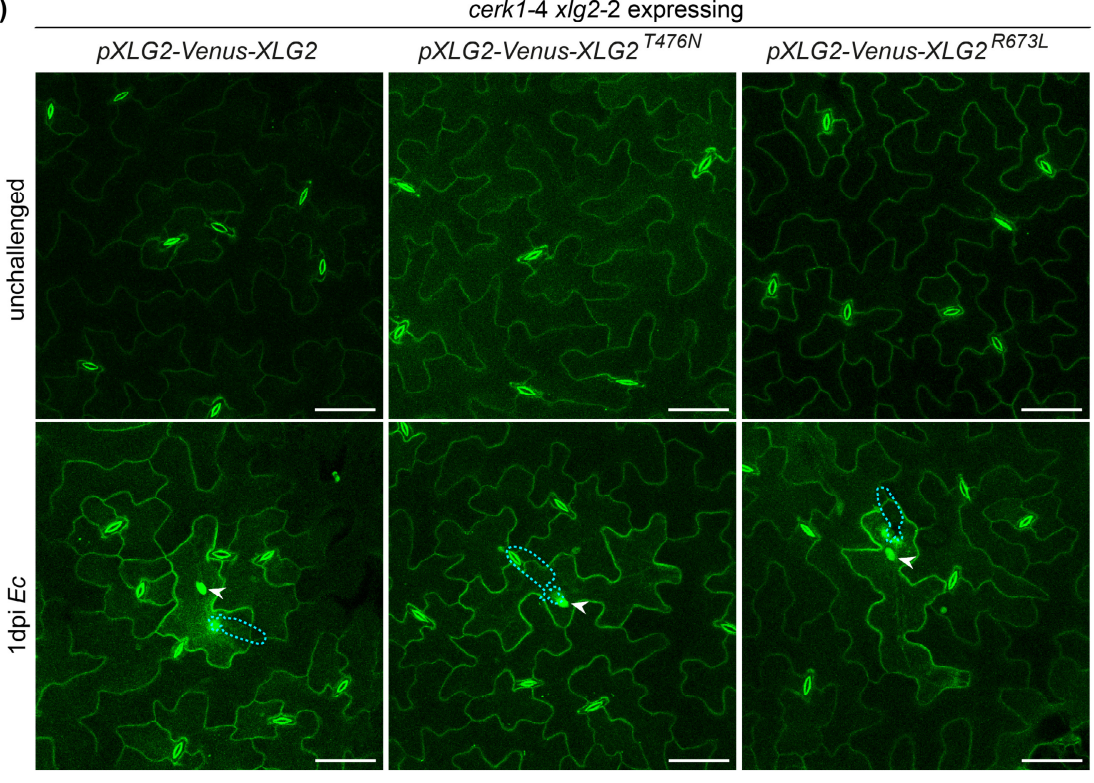

(b)
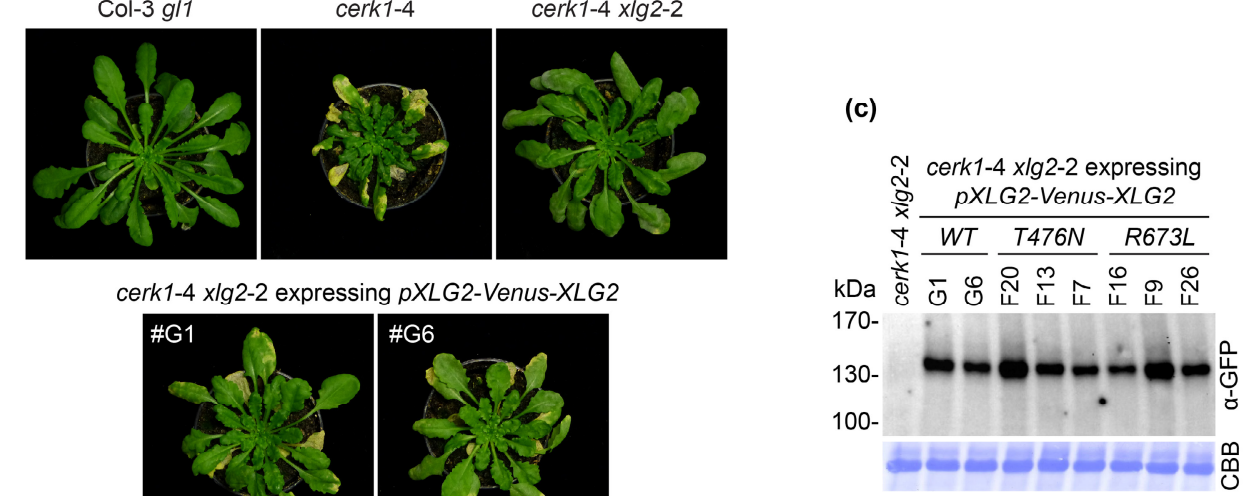

cerk1-4 xlg2-2 expressing $p X L G 2-V e n u s-X L G 2$
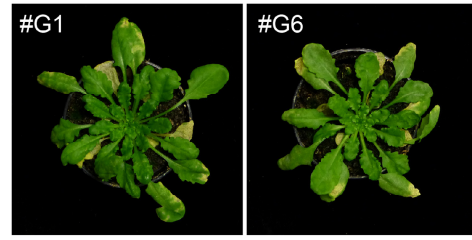

cerk1-4 xlg2-2 expressing $p X L G 2-V e n u s-X L G 2^{\text {T476N }}$
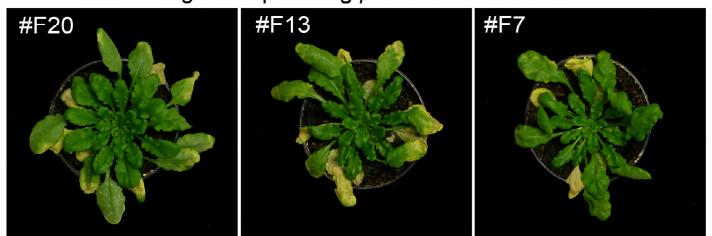

cerk1-4 xlg2-2 expressing $p X L G 2-V e n u s-X L G 2^{R 673 L}$
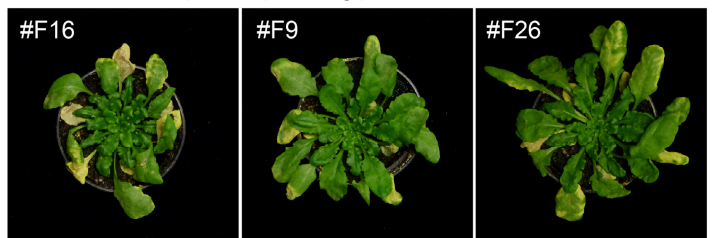

Figure S4: XLG2 GTP binding and GTPase activity are not required for cerk1-4 phenotype formation.

Transgenic cerk1-4 $x / g 2-2$ lines expressing $p X L G 2-V e n u s-X L G 2$, Venus-XLG2 ${ }^{T 476 N}$ or Venus-XLG2 ${ }^{R 673 L}$ were characterized

(a) Representative CLSM images of unchallenged and infected (1 dpi E. cruciferarum) plants. Pictures are maximum projections of z-stacks spanning the epidermal cell layer. Nuclei in attacked cells are marked by arrowheads and the positions of fungal spores are outlined by dashed blue lines. Scale bar $=50 \mu \mathrm{m}$. (b) The indicated transgenic lines and controls were inoculated with E. cruciferarum and the macroscopic phenotype was documented 14dpi. Images of two or three independent lines are shown. (c) Western Blots detecting Venus-XLG2 in the lines presented in (b) after . cruciferarum infection. $\mathrm{CBB}=$ Coomassie Brilliant Blue stained membrane. 
Table S1: Oligonucleotides used in this study

\begin{tabular}{|c|c|c|}
\hline Name & Sequence $5^{\prime}$-> 3' & Purpose \\
\hline EP209 & $\begin{array}{l}\text { ACTGCAGGCGCGCCTGGAGGAGCATAGTGTGATTATTT } \\
\text { AC }\end{array}$ & $\begin{array}{l}\text { Fwd primer for generation of genomic XLG2 } \\
\text { construct for complementation containing } \\
\text { Ascl site }\end{array}$ \\
\hline EP210 & TGAGCTGGATCCTCAAGAGGACGAGCTGGCCTCTATG & $\begin{array}{l}\text { Rev primer for generation of genomic } X L G 2 \\
\text { construct for complementation containing } \\
\text { BamHI site }\end{array}$ \\
\hline CM82 & $\begin{array}{l}\text { GTAACGCCAGGGTTTTCCCAGTCACGACGGGCGCGCCC } \\
\text { CTGGAGGAGCATAGTGTGATTATTTACGAGAGTG }\end{array}$ & $\begin{array}{l}\text { Fwd primer for amplification of the } X L G 2 \\
\text { promoter with additional pRS426 homology } \\
\text { and Ascl site }\end{array}$ \\
\hline CM83 & $\begin{array}{l}\text { GCGGATAACAATTTCACACAGGAAACAGCGGATCCTCA } \\
\text { AGAGGACGAGCTGGCCTCTATGCTAGTAG }\end{array}$ & $\begin{array}{l}\text { Rev primer for amplification of } X L G 2 \text { with } \\
\text { additional pRS426 homology and BamHI site }\end{array}$ \\
\hline CM92 & $\begin{array}{l}\text { GGTGAACAGCTCCTCGCCCTTGCTCACCATCTTCTTACC } \\
\text { CAATCAAGCACACATACAAACCC }\end{array}$ & $\begin{array}{l}\text { Rev primer for amplification of } X L G 2 \\
\text { promoter with homology to Venus }\end{array}$ \\
\hline CM93 & $\begin{array}{l}\text { AGGTAATAACTTTCTTATAACTGCAGCCATCGCTCCAGC } \\
\text { GCCCTTGTACAGCTCGTCCATGCCGAGAGTGATCCC }\end{array}$ & $\begin{array}{l}\text { Rev primer for amplification of Venus with } \\
\text { homology to XLG2 with additional YAGA } \\
\text { linker }\end{array}$ \\
\hline CM94 & ATGGCTGCAGTTATAAGAAAGTTATTACCTTTC & Fwd primer for $X L G 2$ amplification \\
\hline JE23 & ATGGTGAGCAAGGGCGAGGAGC & Fwd primer for Venus amplification \\
\hline JF18 & GCATGAAGGGATCCACTAGTTCTAGAGTCCGCAA & $\begin{array}{l}\text { Introduction of Notl site to pGreenll-0229 } \\
\text { pXLG2-Venus-XLG2 }\end{array}$ \\
\hline JF17 & TGCGGCCGCAGAGGACGAGCTGGCCTCTATG & $\begin{array}{l}\text { Introduction of Notl site to pGreenll-0229 } \\
\text { pXLG2-Venus-XLG2 }\end{array}$ \\
\hline JF19 & GGCCCCTAAGAAGAAGAGAAAGGTTGGAGGATGAG & introducing C-terminal NLS \\
\hline JF20 & GATCCTCATCCTCCAACCTTTCTCTTCTTCTTAGG & introducing C-terminal NLS \\
\hline JF21 & $\begin{array}{l}\text { GGCCCTCCAATTACCACCTTTGGAAAGACTAACACTGT } \\
\text { GAG }\end{array}$ & introducing C-terminal NES \\
\hline JF22 & $\begin{array}{l}\text { GATCCTCACAGTGTTAGTCTTTCCAAAGGTGGTAATTG } \\
\text { GAG }\end{array}$ & introducing C-terminal NES \\
\hline JF30 & GGCCCCTAAGACGAAGAGAAAGGTTGGAGGATGAG & introducing C-terminal nls \\
\hline JF31 & GATCCTCATCCTCCAАССTTTCTCTTCGTCTTAGG & introducing C-terminal nls \\
\hline JF32 & $\begin{array}{l}\text { GGCCCTCCAAGCACCACCTGCGGAAAGAGCAACACTGT } \\
\text { GAG }\end{array}$ & introducing C-terminal nes \\
\hline JF33 & $\begin{array}{l}\text { GATCCTCACAGTGTTGCTCTTTCCGCAGGTGGTGCTTG } \\
\text { GAG }\end{array}$ & introducing C-terminal nes \\
\hline JF7 & TTATGCGCTGTGTTATCTCTGCCAGTTCCTCCG & Mutagenesis nls426 fwd \\
\hline JF8 & $\begin{array}{l}\text { TAATTTTGTTCCCGCCTGTAAAAATAATATCCTTCGTTG } \\
\text { TCTTTAG }\end{array}$ & Mutagenesis nls426 rev \\
\hline JF27 & GGGAGGCAAGGTTCTTTTTGCTTTTCACCTTTG & Mutagenesis nes387 fwd \\
\hline
\end{tabular}




\begin{tabular}{|c|c|c|}
\hline JF28 & GTACCCTCTGGCTTGGTTATTTCCCGGCC & Mutagenesis nes387 rev \\
\hline JF41 & CGGGCCCAGTTGGGGAACCGGTTT & Mutagenesis C214/217A fwd \\
\hline JF42 & GTAAGCCGATCCTCTTTTTACCTTTCCTTTC & Mutagenesis C214/217A rev \\
\hline JF49 & AAATACGCTTTCAACGCTGTGCGCAGAGCCATGGGT & Mutagenesis C229/232/237/240A fwd \\
\hline JF50 & $\begin{array}{l}\text { GGCATCGGCGACAATAGCGACTTCCTTCTCAGTAAACC } \\
\text { GGTTC }\end{array}$ & Mutagenesis C229/232/237/240A rev \\
\hline JF51 & GCTGCCATTGGTTATAGGATTGATGAGTC & Mutagenesis C254/257A fwd \\
\hline JF52 & TTGAGCCTTTCTTCCTTCGGGCATC & Mutagenesis C254/257A rev \\
\hline EP220 & AGTTTCGGATGTGGGACCTAGAG & $\begin{array}{l}\text { Amplification of pGreenll-0229 backbone } \\
\text { fragment for Gibson assembly, fwd primer }\end{array}$ \\
\hline EP625 & TTATAACTGCAGCCATGGCTCCAGCG & $\begin{array}{l}\text { Amplification of pGreenll-0229 backbone } \\
\text { fragment for Gibson assembly, rev primer }\end{array}$ \\
\hline EP624 & GCTGGAGCCATGGCTGCAGTTATAAG & $\begin{array}{l}\text { Amplification of 8S-A and 27S/T-A synthetic } \\
\text { DNA for Gibson Assembly, fwd primer }\end{array}$ \\
\hline EP629 & TCTAGGTCCCACATCCGAAACTC & $\begin{array}{l}\text { Amplification of 8S-A and 27S/T-A synthetic } \\
\text { DNA for Gibson Assembly, rev primer }\end{array}$ \\
\hline
\end{tabular}

960

961

962

963

964

965

966

967

968

Table S2: Overview of transgenic XLG2-FLAG lines in the cerk1-4 xlg2-2 background

* Expression of fusion proteins confirmed via Western blotting. Phenotype evaluation after E. cruciferarum (EC) infection in T1 generation.

\begin{tabular}{|c|c|c|c|}
\hline $\begin{array}{c}\text { Transgene } \\
\text { (expressed from 35S promoter) }\end{array}$ & $\begin{array}{c}\text { Independent lines } \\
\text { generated }\end{array}$ & $\begin{array}{c}\text { Independent lines } \\
\text { analysed* } \\
\text { (complementation rate) }\end{array}$ & $\begin{array}{c}\text { Apparent mass in } \\
\text { Western Blots }\end{array}$ \\
\hline$X L G 2-F L A G W T$ & 18 & $18(100 \%)$ & $\sim 110 \mathrm{kDa}$ \\
\hline$X L G 2^{4 S-A}-F L A G$ & 20 & $20(100 \%)$ & WT-like \\
\hline$X L G 2^{4 S-D}-$ FLAG & 16 & $16(100 \%)$ & WT-like \\
\hline
\end{tabular}


Table S3: Overview of transgenic Venus-XLG2 lines in the $x$ lg2-2 background

* Expression levels and localisation of Venus fusion proteins confirmed via CLSM and/or Western blotting.

Phenotype evaluation after E. cruciferarum (Ec) infection in T1 and/or T2 generation. All lines showed a WT-like growth and cell death phenotype. ${ }^{* *}$ In lines with very high expression levels, faint nuclear signals were observed.

\begin{tabular}{|c|c|c|c|c|c|}
\hline $\begin{array}{c}\text { Transgene } \\
\text { (expressed from } \\
\text { XLG2 promoter) }\end{array}$ & $\begin{array}{c}\text { Independent } \\
\text { lines } \\
\text { generated }\end{array}$ & $\begin{array}{c}\text { Independent } \\
\text { lines } \\
\text { analysed* }\end{array}$ & $\begin{array}{c}\text { Subcellular } \\
\text { localisation in } \\
\text { unchallenged } \\
\text { cells }\end{array}$ & $\begin{array}{c}\text { Subcellular } \\
\text { localisation } \text { Ec } \\
\text { infected cells }\end{array}$ & $\begin{array}{c}\text { Apparent } \\
\text { mass in } \\
\text { Western } \\
\text { Blots }\end{array}$ \\
\hline Venus-XLG2 WT & 42 & 6 & cell periphery** & $\begin{array}{c}\text { nucleus, cell } \\
\text { periphery, } \\
\text { cytoplasmic strands }\end{array}$ & $\sim 140 \mathrm{kDa}$ \\
\hline Venus-XLG2 2 E293K & 15 & 6 & $\begin{array}{c}\text { nucleus, very } \\
\text { faint cell } \\
\text { periphery }\end{array}$ & $\begin{array}{c}\text { nucleus, very faint } \\
\text { cell periphery }\end{array}$ & reduced \\
\hline
\end{tabular}

Table S4: Overview of transgenic Venus-XLG2 lines in the cerk1-4 xlg2-2 background

* Expression levels and localisation of Venus fusion proteins confirmed via CLSM and/or Western blotting, Phenotype evaluation after E. cruciferarum ( $E C)$ infection in T1 and/or T2 generation. ** In lines with very high expression levels, faint nuclear signals were observed. *** Occasionally very faint nuclear signals were observed in E. cruciferarum-attacked cells.

\begin{tabular}{|c|c|c|c|c|c|}
\hline $\begin{array}{c}\text { Transgene } \\
\text { (expressed from } \\
\text { XLG2 promoter) }\end{array}$ & $\begin{array}{l}\text { Independent } \\
\text { lines } \\
\text { generated }\end{array}$ & $\begin{array}{l}\text { Independent lines } \\
\text { analysed* } \\
\text { (complementation } \\
\text { rate) }\end{array}$ & $\begin{array}{c}\text { Subcellular } \\
\text { localisation in } \\
\text { unchallenged } \\
\text { cells }\end{array}$ & $\begin{array}{c}\text { Subcellular } \\
\text { localisation in } \\
\text { Ec infected cells }\end{array}$ & $\begin{array}{l}\text { Apparent } \\
\text { mass in } \\
\text { Western } \\
\text { Blots }\end{array}$ \\
\hline Venus-XLG2 WT & 46 & $14(100 \%)$ & $\begin{array}{c}\text { cell } \\
\text { periphery** }\end{array}$ & $\begin{array}{c}\text { nucleus, cell } \\
\text { periphery, } \\
\text { cytoplasmic strands }\end{array}$ & $\sim 140 \mathrm{kDa}$ \\
\hline Venus-XLG2 $2^{E 293 K}$ & 21 & $11(0 \%)$ & $\begin{array}{c}\text { nucleus, very } \\
\text { faint cell } \\
\text { periphery }\end{array}$ & $\begin{array}{l}\text { nucleus, very faint } \\
\text { cell periphery }\end{array}$ & reduced \\
\hline Venus-XLG2-nes & 31 & $14(100 \%)$ & WT-like & WT-like & WT-like \\
\hline Venus-XLG2-NES & 36 & $8(100 \%)$ & cell periphery & $\begin{array}{c}\text { cell periphery, } \\
\text { cytoplasmic strands }\end{array}$ & WT-like \\
\hline Venus-XLG2-nls & 41 & $12(100 \%)$ & WT-like & WT-like & WT-like \\
\hline Venus-XLG2-NLS & 27 & $12(100 \%)$ & $\begin{array}{c}\text { nucleus, cell } \\
\text { periphery }\end{array}$ & $\begin{array}{c}\text { nucleus, cell } \\
\text { periphery }\end{array}$ & WT-like \\
\hline Venus-XLG2 $2^{\text {nes } 387}$ & 54 & $25(0 \%)$ & E293K-like & E293K-like & $\begin{array}{l}\text { E293K- } \\
\text { like }\end{array}$ \\
\hline Venus-XLG2 $2^{\text {n/s426 }}$ & 25 & $10(100 \%)$ & cell periphery & $\begin{array}{l}\text { cell periphery, } \\
\text { cytoplasmic } \\
\text { strands*** }\end{array}$ & WT-like \\
\hline Venus-XLG2 $2^{T 476 N}$ & 23 & $16(94 \%)$ & WT-like & WT-like & WT-like \\
\hline Venus-XLG2 $2^{R 673 L}$ & 24 & $13(100 \%)$ & WT-like & WT-like & WT-like \\
\hline $\begin{array}{c}\text { Venus-XLG2 } \\
\text { c214/217A }\end{array}$ & 16 & $16(0 \%)$ & E293K-like & E293K-like & $\begin{array}{l}\text { E293K- } \\
\text { like }\end{array}$ \\
\hline $\begin{array}{c}\text { Venus-XLG2 } \\
\text { C229/232/237/240A }\end{array}$ & 12 & $12(0 \%)$ & E293K-like & E293K-like & $\begin{array}{l}\text { E293K- } \\
\text { like }\end{array}$ \\
\hline $\begin{array}{c}\text { Venus-XLG2 } \\
\text { C254/257A }\end{array}$ & 21 & $21(0 \%)$ & E293K-like & E293K-like & $\begin{array}{l}\text { E293K- } \\
\text { like }\end{array}$ \\
\hline Venus-XLG2 ${ }^{8 S-A}$ & 48 & $6(100 \%)$ & WT-like & WT-like & WT-like \\
\hline Venus-XLG2 ${ }^{27 S / T-A}$ & 12 & $5(100 \%)$ & WT-like & WT-like & WT-like \\
\hline
\end{tabular}


Table S5: Overview of transgenic Venus-XLG2 lines in the agb1-2 background

* Expression levels and localisation of Venus fusion proteins confirmed via CLSM and Western blotting.

988

\begin{tabular}{|c|c|c|c|c|}
\hline $\begin{array}{c}\text { Transgene } \\
\text { (expressed from } \\
\text { XLG2 promoter) }\end{array}$ & $\begin{array}{c}\text { Independent } \\
\text { lines } \\
\text { generated }\end{array}$ & $\begin{array}{c}\text { Independent } \\
\text { lines } \\
\text { analysed* }\end{array}$ & $\begin{array}{c}\text { Subcellular localisation in } \\
\text { unchallenged cells }\end{array}$ & $\begin{array}{c}\text { Apparent mass in } \\
\text { Western Blots }\end{array}$ \\
\hline Venus-XLG2 WT & 37 & 6 & cell periphery, nucleus & $\begin{array}{c}\text { reduced compared to } \\
\text { AGB1 background }\end{array}$ \\
\hline Venus-XLG2E293K & 36 & 6 & $\begin{array}{c}\text { nucleus, very faint cell } \\
\text { periphery }\end{array}$ & reduced \\
\hline
\end{tabular}

